\title{
Effects of a future warmer ocean on the coexisting copepods Calanus finmarchicus and C. glacialis in Disko Bay, western Greenland
}

\author{
Sanne Kjellerup ${ }^{1,2,4}$, Michael Dünweber ${ }^{1}$, Rasmus Swalethorp ${ }^{1,4}$, \\ Torkel Gissel Nielsen ${ }^{1,2,4, *}$, Eva Friis Møller ${ }^{1}$, Stiig Markager ${ }^{1}$, Benni Winding Hansen ${ }^{3}$ \\ ${ }^{1}$ Department of Bioscience, Aarhus University, Frederiksborgvej 399, 4000 Roskilde, Denmark \\ ${ }^{2}$ Greenland Climate Research Center, Greenland Institute of Natural Resources, PO Box 570, 3900 Nuuk, Greenland \\ ${ }^{3}$ Roskilde University, Department of Environmental, Social and Spatial Change, 4000 Roskilde, Denmark \\ ${ }^{4}$ Present address: National Institute of Aquatic Resources, DTU Aqua, Section for Ocean Ecology and Climate, \\ Technical University of Denmark, Kavalergården 6, 2920 Charlottenlund, Denmark
}

\begin{abstract}
The effects of temperature and food was examined for Calanus finmarchicus and $C$. glacialis during 3 phases of the phytoplankton spring bloom in Disko Bay, western Greenland. The 2 species were collected during pre-bloom, bloom, and post-bloom and exposed to temperatures from 0 to $10^{\circ} \mathrm{C}$, combined with deficient or excess food. Fecal pellet and egg production were measured as indices for grazing and secondary production, respectively. Furthermore, changes in body carbon, nitrogen, and lipid content were measured. C. glacialis sampled before the bloom and incubated with excess food exhibited high specific egg production at temperatures between 0 and $2.5^{\circ} \mathrm{C}$. Higher temperatures did not increase egg production considerably, whereas egg production for C. finmarchicus more than tripled between 2.5 and $5^{\circ} \mathrm{C}$. Starved C. glacialis produced eggs at all temperatures stimulated by increasing temperatures, whereas starved $C$. finmarchicus needed temperatures above $5^{\circ} \mathrm{C}$ to produce eggs fueled by their lipid stores. Few $C$. finmarchicus had mature gonads at the initiation of the pre-bloom and bloom experiment, and egg production of C. finmarchicus therefore only increased as the ratio of individuals with mature gonads increased. During the bloom, both C. glacialis and C. finmarchicus used the high food availability for egg production, while refueling or exhausting their lipid stores, respectively. Finally, during the post-bloom experiment, production was low by C. finmarchicus, whereas C. glacialis had terminated production. Our results suggest that a future warmer ocean will reduce the advantage of early spawning by $C$. glacialis and that $C$. finmarchicus will become increasingly prevalent.
\end{abstract}

KEY WORDS: Calanus finmarchicus · Calanus glacialis · Global warming · Egg production · Fecal pellet production $\cdot$ Population dynamics

Resale or republication not permitted without written consent of the publisher

\section{INTRODUCTION}

Arctic marine ecosystems are experiencing substantial changes. Climate change is directly and indirectly impacting sea ice coverage and circulation patterns and thereby the underwater light climate, availability of nutrients, and the mixing layer depth
(Rysgaard et al. 1999, Comiso 2002, Tremblay \& Gagnon 2009). The seasonality in these factors drives the characteristic annual patterns of plankton succession, and changes in these forcing factors will greatly impact the succession and productivity of Arctic marine ecosystems (Kitaysky \& Golubova 2000, Ringuette et al. 2002, Falk-Petersen et al. 2007, Kahru et 
al. 2011). The break-up of sea ice triggers a short and intense phytoplankton bloom when light enters the water column (Dünweber et al. 2010).

The key grazers of phytoplankton in the Arctic are copepods of the genus Calanus (Madsen et al. 2001). The proportion of lipid in the dry mass increases from $10-20 \%$ in phytoplankton to $50-70 \%$ in Calanus (Falk-Petersen et al. 2007). This lipid-based energy flux is believed to be the primary reason for the large stocks of fish, birds, and mammals present in Arctic waters (Karnovsky et al. 2003, Falk-Petersen et al. 2007, Laidre et al. 2007). Phytoplankton grazed by Calanus species are either used for growth, maturation of gonads and oocytes, and egg production or converted into lipids (Falk-Petersen et al. 2007). The accumulation of lipids allows Calanus species to withstand long periods of food shortage during their winter hibernation close to the seafloor (FalkPetersen et al. 2007).

It is essential that the upward migration of Calanus from the overwintering depths match the phytoplankton bloom in order for them to reproduce successfully (Madsen et al. 2001, Hirche \& Kosobokova 2003) and subsequently refuel their lipid stores (Lee et al. 2006, Swalethorp et al. 2011). However, it is not known to what extent Arctic Calanus spp. are capable of timing their ascent from the seabed after hibernation to the occurrence of the spring bloom. A mismatch between these events will result in insufficient food quantity and/or quality, and consequently low reproductive success (A. S. Hansen et al. 2003)

Disko Bay on the west coast of Greenland is influenced by sub-Arctic waters of southwestern Greenland and High Arctic waters of Baffin Bay (Buch 1990, Holland et al. 2008, Hansen et al. in press). Disko Bay is located at the southern border of the Arctic sea ice extent, and the average sea ice cover shows high year to year variability. In the bay, an annual mean air

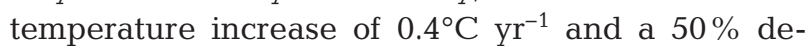
crease in sea ice cover have been observed between 1991 and 2004 (Hansen et al. 2006). In the same period, a tendency for earlier initiation of the spring phytoplankton has been observed (Nielsen \& Hansen 1995, Madsen et al. 2001, S.J. Madsen et al. 2008). This impact of climate change makes Disko Bay an ideal location to investigate the effects of increasing temperatures, change in sea ice cover, and subsequent changes in the development of the phytoplankton and succeeding links in the marine pelagic food web. Furthermore, Disko Bay roughly represents the northern border for the reproduction of the Atlantic Calanus finmarchicus (Gunnerus) and the southern border for C. glacialis (Jaschnov).
These 2 Calanus species have very similar overall morphology, but differ in their life cycle, reproductive strategy, and lipid content, and may therefore respond differently to future climate change (Scott et al. 2000, Falk-Petersen et al. 2007). C. glacialis initiates spawning prior to the spring bloom, with gonad maturation and egg production fueled by internal lipid reserves (i.e. 'capital breeder' sensu Varpe et al. 2009), most likely an adaptation to the unpredictable food conditions in the Arctic environment (Conover \& Huntley 1991, Falk-Petersen et al. 2009). However, to achieve maximum egg production, C. glacialis needs to feed (Hirche \& Kattner 1993). On the other hand, C. finmarchicus is dependent on food to finish gonad maturation and initiate spawning (i.e. 'income breeder' sensu Varpe et al. 2009).

The air temperatures in the Arctic are predicted to increase by 4 to $7^{\circ} \mathrm{C}$ over the next 100 yr (ACIA 2004). Such a time scale is comparable to $\sim 100$ Calanus generations and will obviously increase the selective pressures of the Calanus populations and allow them to evolve and adapt to the new environmental situation. Such adaptations are extremely difficult to predict or quantify. However, the temperature changes will not necessarily happen gradually, but sometimes rapidly with large increments, e.g. 1 to $2^{\circ} \mathrm{C}$ in bottom water temperature over 1 mo as observed in Disko Bay in 1996 to 1997 (Holland et al. 2008, Hansen et al. in press). Little is known on how flexibly Calanus can cope with such rapid changes, but quantifying this through experiments will help us to more reliably predict the response of species to such changes, given their current physiological and behavioral adaptations. Calanus spp. in Disko Bay encounter a range of temperatures during their migration. In the spring, this can range from $3-4^{\circ} \mathrm{C}$ at the bottom to $-1.8^{\circ} \mathrm{C}$ in surface water, but later in May when a thermocline is established, they can potentially be exposed to gradients of 8 to $10^{\circ} \mathrm{C}$. Here we present results of experimental investigations of Calanus conducted in the laboratory that simulates a warmer environment.

Our hypothesis was that Calanus glacialis may lose its present advantage of early spawning compared to C. finmarchicus (Niehoff et al. 2002) in a future warmer ocean. The hypothesis was tested by evaluating effects of food availability, temperature, and timing of the phytoplankton bloom on grazing (fecal pellet production) and egg production as well as the biochemical composition of $C$. finmarchicus and C. glacialis through 3 successive phases during the spring bloom. 


\section{MATERIALS AND METHODS}

\section{Field sampling}

The copepods were sampled in Disko Bay close to Qeqertarsuaq in West Greenland from holes drilled in the sea ice $\left(69^{\circ} 14^{\prime} \mathrm{N}, 53^{\circ} 30^{\prime} \mathrm{W}\right)$ on 22 March and from RV 'Porsild' (Arctic Station, University of Copenhagen) on 22 April and 28 May 2008 at a monitoring station used in previous studies (Nielsen \& Hansen 1995, Levinsen et al. 2000, Madsen et al. 2001, Niehoff et al. 2002, S.J. Madsen et al. 2008), 1 nautical mile off the Qeqertarsuaq harbor $\left(69^{\circ} 14^{\prime} \mathrm{N}\right.$, $53^{\circ} 23^{\prime} \mathrm{W}_{\text {; Fig. }}$ ). Additional information on oceanography, plankton succession, in situ production, and biochemical composition of the Calanus spp. are reported by Dünweber et al. (2010) and Swalethorp et al. (2011).
Chl $a=0.313 x, \mathrm{r}^{2}=0.98, \mathrm{n}=14$, for chl $a<250 \mu \mathrm{g}^{-1}$

Three consecutive 2 wk experiments were conducted, initiated on $24 \mathrm{March}, 24$ April, and 30 May. The experimental setup included 5 temperatures: $0,2.5,5,7.5$, and $10^{\circ} \mathrm{C}$. This temperature range was chosen based on the ACIA (2004) prediction for a future climate. All experiments were carried out in $0.2 \mu \mathrm{m}$ filtered seawater with 2 treatments, without food or with saturated food conditions (added $15 \mu \mathrm{g}$ $\mathrm{chl} \mathrm{a} \mathrm{l}^{-1}$ of Thalassiosira weissflogii, equal to $690 \mu \mathrm{g} \mathrm{C}$ $\mathrm{I}^{-1}$; Reigstad et al. 2005). The experiments were conducted in 52001 temperature-controlled thermoboxes filled with water. The temperature was logged every 15 min using Hobo thermo-loggers (Table 1).

In each thermo-box, 4 buckets were placed, each filled with $7.5 \mathrm{l}$ of $0.2 \mu \mathrm{m}$ filtered seawater and containing a cylinder $(28.3 \mathrm{~cm}$ high and $18 \mathrm{~cm}$ in dia-

\section{Phytoplankton culture and experimental set-up}

A culture of the diatom Thalassiosira weissflogii was grown in 151 aerated algal plastic bags filled with $0.2 \mu \mathrm{m}$ filtered seawater (salinity $33 \pm 2$ ). The cultures were diluted daily and kept in exponential growth phase. $\mathrm{B}_{1}$ medium $\left(1 \mathrm{ml} \mathrm{l}^{-1}\right)$ and silicate $\left(1.1 \mathrm{ml} \mathrm{l}^{-1}\right)$ were added every second day. Vitamins $\left(1 \mathrm{ml} \mathrm{l}^{-1}\right)$ were added weekly (Hansen 1989). The bags were exposed to a $12: 12 \mathrm{~h}$ light:dark cycle with $50 \mu \mathrm{E} \mathrm{m}^{-2} \mathrm{~s}^{-1}$, at $20 \pm 2^{\circ} \mathrm{C}$. The chlorophyll a $(\mathrm{chl}$ a) concentrations were estimated from a linear relationship between $\mathrm{chl} a$ and the fluorescence measured directly in the culture $(x)$ :
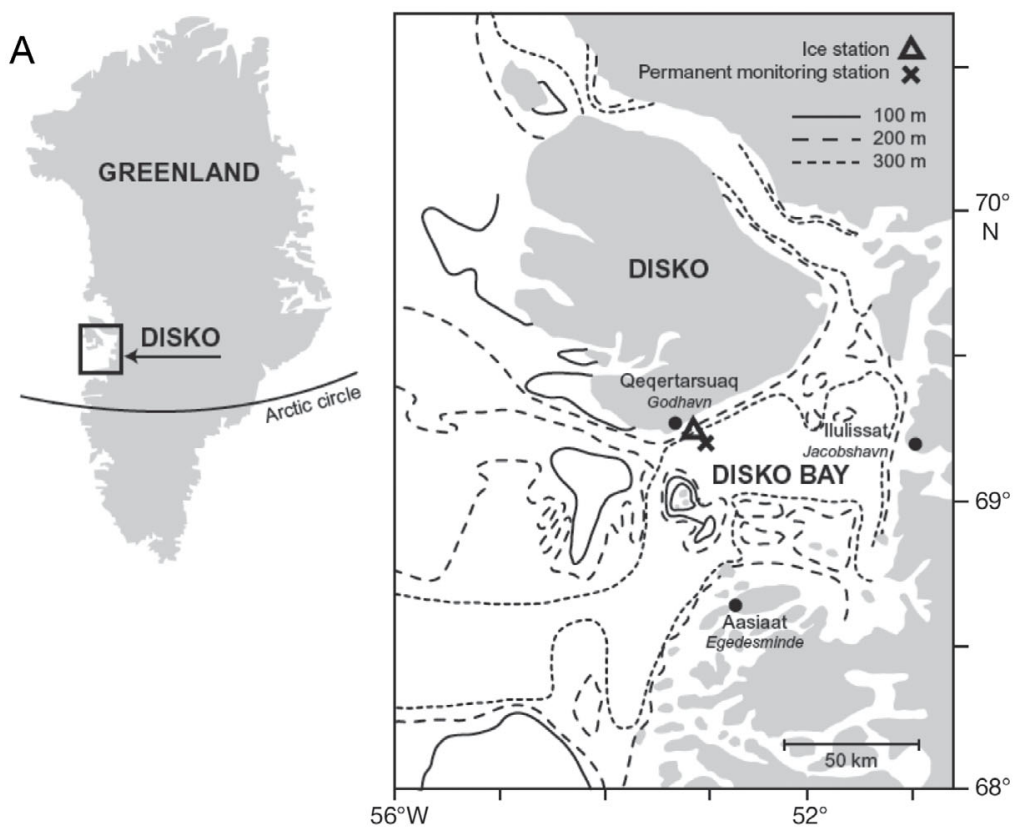

Fig. 1. (A) Sampling location in Disko Bay (West Greeenland). Overview and detailed map. (B) Water temperature (isolines) in ${ }^{\circ} \mathrm{C}$, chl a concentration (shaded area) in $\mu \mathrm{g} \mathrm{l^{-1 }}$ (right scale), and nitrate concentration at $0.5 \mu \mathrm{M}$ (dashed line) and $1.0 \mu \mathrm{M}$ (solid line) throughout the study period (modified from Swalethorp et al. 2011). Grey bar marks the breakup of sea ice cover. Black vertical lines represent dates on which the copepods used in the experiment were sampled (pre-bloom, bloom, and post-bloom)

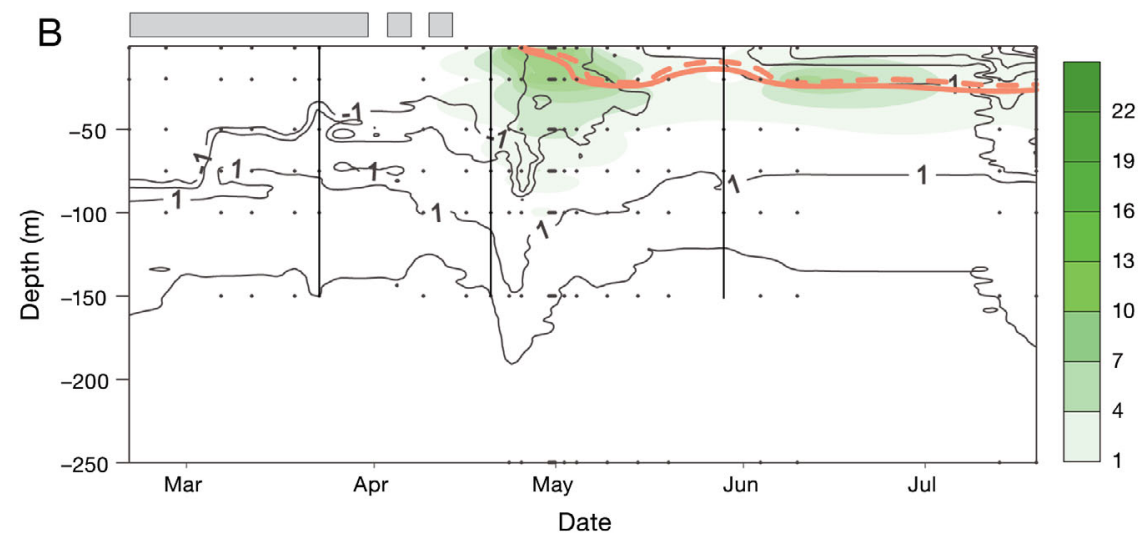


Table 1. Measured temperature (mean $\pm \mathrm{SD}$ ) during the laboratory experiments, logged every $15 \mathrm{~min}$

\begin{tabular}{|lrrr|}
\hline \multirow{2}{*}{$\begin{array}{l}\text { Intended } \\
\text { temperature }\left({ }^{\circ} \mathrm{C}\right)\end{array}$} & Pre-bloom & \multicolumn{3}{c|}{ Bloom } & \multicolumn{1}{c|}{ Post-bloom } \\
\hline 0 & $-0.2 \pm 0.4$ & $0.4 \pm 0.4$ & $0.4 \pm 0.2$ \\
2.5 & $2.6 \pm 0.4$ & $2.7 \pm 0.4$ & $2.6 \pm 0.4$ \\
5 & $5.1 \pm 0.5$ & $4.3 \pm 0.4$ & $4.8 \pm 0.4$ \\
7.5 & $7.2 \pm 0.2$ & $7.0 \pm 0.2$ & $7.5 \pm 0.3$ \\
10 & $10.5 \pm 0.4$ & $10.5 \pm 0.2$ & $10.3 \pm 0.3$ \\
\hline
\end{tabular}

meter) with an egg separator (400 $\mu \mathrm{m}$ mesh). Two of these buckets contained Calanus finmarchicus and the other 2 contained C. glacialis. For each of the species, one of the buckets was kept with filtered seawater and one with Thalassiosira weissflogii-enriched filtered seawater. Every $24 \mathrm{~h}$, the cylinders were gently transferred to new buckets containing $2.5 \mathrm{l}$ of seawater at the appropriate temperature, and eggs and pellets were collected from the bottom of the old bucket by filtration through a $50 \mu \mathrm{m}$ filter. Thus, each experiment included 14 observations over time, per treatment. After filtration of fecal pellets and eggs, 51 of the seawater were reused. The food concentration in the recycled water was measured and adjusted by addition of $T$. weissflogii to obtain the desired $15 \mu \mathrm{g}$ chl $a l^{-1}$.

\section{Sampling and sorting of copepods and acclimation}

Calanus finmarchicus and $C$. glacialis were collected with a WP-2 nylon net $(200 \mu \mathrm{m}$ mesh with a closed $1 \mathrm{l}$ cod-end). After collection, the copepods were kept in a thermo-box at approximately $0^{\circ} \mathrm{C}$. In the laboratory, 100 adult females of each species were sorted under a dissection microscope and identified according to the morphological and pigmentation criteria illustrated in Fig. 2 and Table 2. Sorting was done under a dissecting microscope where a small Petri dish containing copepods and seawater was placed in a larger Petri dish with snow. The bottles were kept dark at $0^{\circ} \mathrm{C}$ until the next day. The following day, the cope- pods were inspected, and only active and undamaged females were transferred to new $600 \mathrm{ml}$ beakers containing $0.2 \mu \mathrm{m}$ filtered seawater with either $30 \mathrm{C}$. finmarchicus (25 in the pre-bloom experiment) or 20 C. glacialis (15 in the pre-bloom experiment).

To acclimatize the copepods, the bottles containing copepods later used in the experiment at 0 and $2.5^{\circ} \mathrm{C}$ were kept at $0^{\circ} \mathrm{C}$ for another $24 \mathrm{~h}$, whereas the copepods used in the experiment at $5,7.5$, and $10^{\circ} \mathrm{C}$ were kept at $5^{\circ} \mathrm{C}$. After $24 \mathrm{~h}$, the copepods were released into the experimental cylinders (no copepod had died).

\section{Eggs, fecal pellets, and mortality}

In addition to counting all eggs and fecal pellets, the length and width of 30 fecal pellets and eggs were measured 3 times ( 4 in Expt 1 ) in each experiment for each treatment (Days 1, 7, and 14). Only pellets 3 times as long or longer than the width were considered. Copepods that died during the experiments were removed and their prosome length measured. In the analysis, the copepods were assumed to have been alive until removal. These were not included in the carbon and lipid measurements. Mortality was on average $7.5 \%$ for Calanus finmarchicus and $8.5 \%$ for C. glacialis and was not related to temperature or food conditions.

Due to the large number of samples, samples of egg and pellets were fixed in acid Lugol's solution

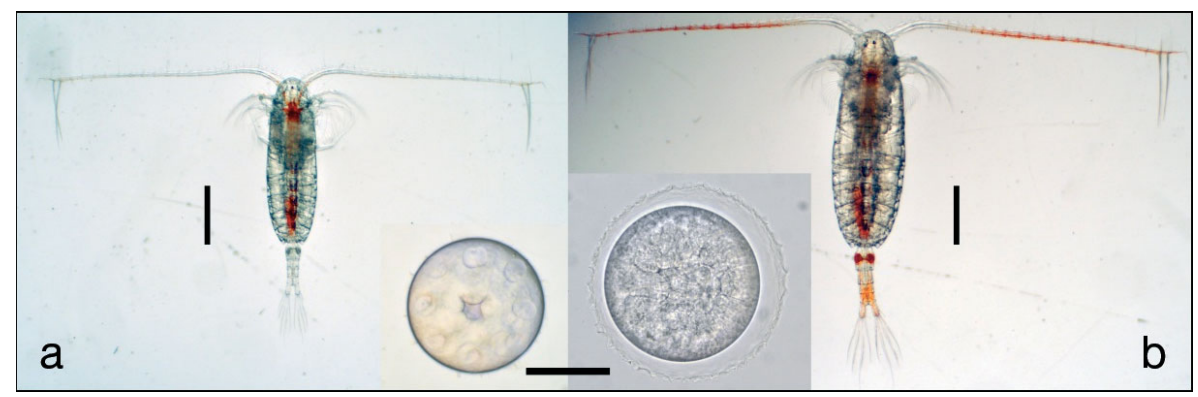

Fig. 2. Calanus finmarchicus and C. glacialis. Morphology and pigmentation used to separate females and eggs of (a) C. finmarchicus from (b) C. glacialis. Scale bars are $1 \mathrm{~mm}$ and $0.1 \mathrm{~mm}$ for females and eggs, respectively. Photo by S. Kjellerup

Table 2. Identification criteria for Calanus finmarchicus and C. glacialis. Mean \pm SD (n) prosome length of all females, egg diameter \pm SD (n), and pigmentation of the antennae and genital somites

\begin{tabular}{|lccccc|}
\hline & $\begin{array}{c}\text { Prosome length } \\
(\mathrm{mm})\end{array}$ & $\begin{array}{c}\text { Egg diameter } \\
(\mu \mathrm{m})\end{array}$ & Antennae & $\begin{array}{c}\text { Genital } \\
\text { somite }\end{array}$ & Abdomen \\
\hline C. finmarchicus & $2.7 \pm 0.1(11292)$ & $153 \pm 10(1775)$ & White/pale & White/pale & Pale \\
C. glacialis & $3.5 \pm 0.3(7429)$ & $178 \pm 12(2883)$ & Red & Red & Red \\
\hline
\end{tabular}


(final concentration 2\%) and analyzed within 1 to 6 mo. To detect possible shrinkage due to fixation, approximately 100 fecal pellets were measured for all treatments before and after preservation. There were no significant changes in fecal pellet volume in the treatments with food present $(\mathrm{p}>0.05)$, but in treatments without food, the fecal pellet volumes shrank by $21 \%$ ( $\mathrm{p}<0.001)$. Consequently, all fecal pellets from starved treatments were volume adjusted accordingly. For eggs, no significant shrinking was found for any of the treatments ( $p>0.05)$.

\section{Lipid, carbon, and nitrogen measurements}

When copepods were inspected before acclimation, some were collected for initial lipid, carbon, and nitrogen measurements, and their prosome length was measured. For a more detailed description of the methods applied, see Swalethorp et al. (2011).

The initial carbon and nitrogen content for each experiment was determined on 15 Calanus finmarchicus and 15 C. glacialis. At the end of each experiment, the experimental copepods were stored for lipid, carbon, and nitrogen measurements, with 4 replicates for lipids and 7 for carbon and nitrogen for each species.

Three carbon versus length regressions (initial, starved and fed individuals) were established for approximately 15 individuals from each experiment based on all temperatures and both species (Fig. S1 in the supplement at www.int-res.com/articles/suppl/ m447p087_supp.pdf). These relationships were used to estimate carbon content during the experiment and for normalization of egg and pellet production and lipid content based on measurements of prosome length.

Lipids were measured as triacylglycerol (TAG), phospholipid (PL), and wax esters (WE) as well as total lipid (TL; sum of TAG, PL, and WE). The effects of the treatments for both normalized carbon and lipid content were evaluated as percent changes relative to the initial samples.

\section{Fecal pellet and egg production}

The fecal pellet (FP) volume $\left(\mu^{3}\right)$ was calculated from the length and width assuming that their shapes were cylindrical. The FP volume was converted to carbon $\left(\mathrm{C}_{\mathrm{FP}}, \mu \mathrm{g} \mathrm{C}\right.$ pellet $\left.^{-1}\right)$ using a conversion factor of $8.03 \times 10^{-8} \mu \mathrm{g} \mathrm{C} \mathrm{m}^{-3}$ (Reigstad et al. 2005) for the fed treatment and a conversion factor of $4.75 \times$
$10^{-8} \mu \mathrm{g} \mathrm{C} \mu \mathrm{m}^{-3}$ (Seuthe et al. 2007) for the starved treatment. These 2 conversion factors were based on experiments with comparable food concentrations to this experiment, using Calanus finmarchicus and C. glacialis, respectively.

FP production was counted daily and transformed into specific pellet production ( $\mathrm{SPP}, \mu \mathrm{g} \mathrm{C} \mu \mathrm{g} \mathrm{C} \mathrm{C}^{-1} \mathrm{~d}^{-1}$ ). The cumulative SPP ( $\left.\mathrm{SPP}_{\text {cum }}, \mu \mathrm{g} \mathrm{C} \mu \mathrm{g} \mathrm{C}^{-1}\right)$ is the sum of FPs produced from the start to Day $d$. A clear 2-phase trend was apparent (Figs. 3 \& 4) and modeled as bi-linear relationships:

$$
\begin{aligned}
& \text { if } d \leq l p \text {, then } \mathrm{SPP}_{\text {cum }}=d \times k_{1} \\
& \text { otherwise } \mathrm{SPP}_{\text {cum }}=l p \times k_{1}+k_{2}(d-l p)
\end{aligned}
$$

The termination of the lag phase $(l p)$ is the day $(d)$ where the 2 lines intercept each other. The slope of the first phase, $k_{1}\left(\% \mathrm{C} \mathrm{d}^{-1}\right)$ is derived between $d_{0}$ and $l p$, and $k_{2}$ is the slope between $l p$ and $d_{14}$ (Fig. 5). The model included the constraint that $k_{2} \geq$ $k_{1}$ for the fed treatments and no criteria for the starved treatments. This difference was based on the observation that in some of the starved treatments, production ceased during the experimental period. $k_{2}$ was interpreted to represent the maximum potential $\mathrm{SPP}_{\text {rate(k2) }}\left(\mu \mathrm{g} \mathrm{C} \mu \mathrm{g} \mathrm{C}^{-1} \mathrm{~d}^{-1}\right)$ at the given temperature and food level. If production had ceased in the second phase, $\mathrm{SPP}_{\text {rate(k1) }}$ was used. The parameters in Eq. (2) were estimated using the Proc Nlin procedure in SAS Software (SAS Institute). Initial guesses for slopes and lag phase were provided $\left(k_{1}\right.$ and $k_{2}=0.5$ specific egg production or SPP $\mathrm{d}^{-1}$ and $l=3 \mathrm{~d}$ ). The procedure then estimated the parameter values including SE and $p$ values. The initial guesses did not affect the estimated parameter values within reasonable limits.

The egg volume $\left(\mu \mathrm{m}^{3}\right)$ was calculated assuming a spherical form (Table 3). The egg volume was converted to carbon content using the same conversion factor for Calanus glacialis and $C$. finmarchicus (Hygum et al. 2000; $13.65 \times 10^{-8} \mu \mathrm{g} \mathrm{C}$ $\mu \mathrm{m}^{-3}$ ). The daily specific egg production (SEP), the cumulative SEP $\left(\mathrm{SEP}_{\text {cum }}\right)$, and the potential SEP rate $\left(\mathrm{SEP}_{\text {rate(k2) }}\right)$ were calculated in the same way as the FP production.

\section{Statistical analysis}

The influence of food availability and temperature on FP and egg volume was analyzed using a splitplot variance analysis and random effects systematic analysis (Hicks 1966). The effect of temperature, food availability, and differences between species and 


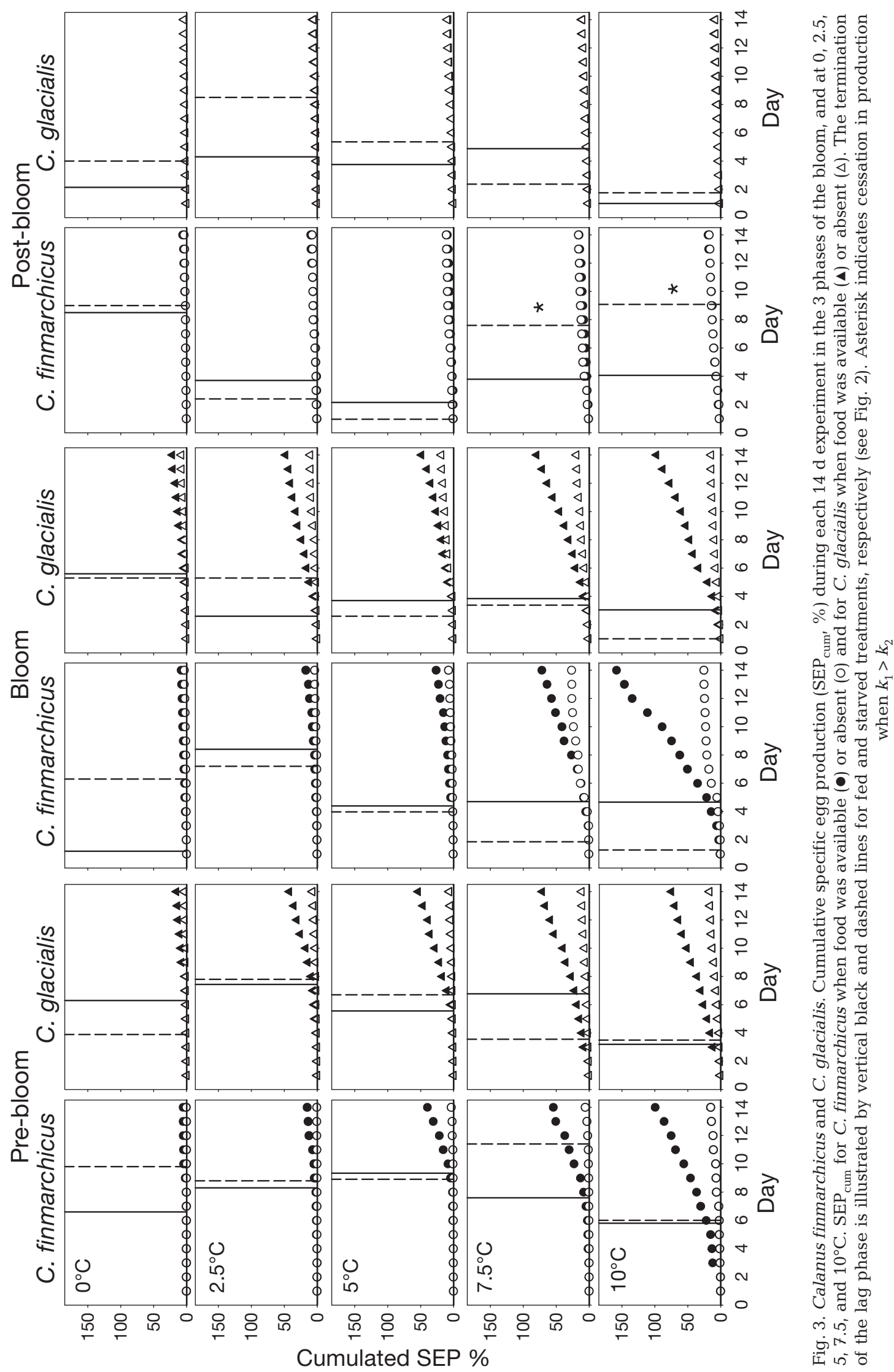




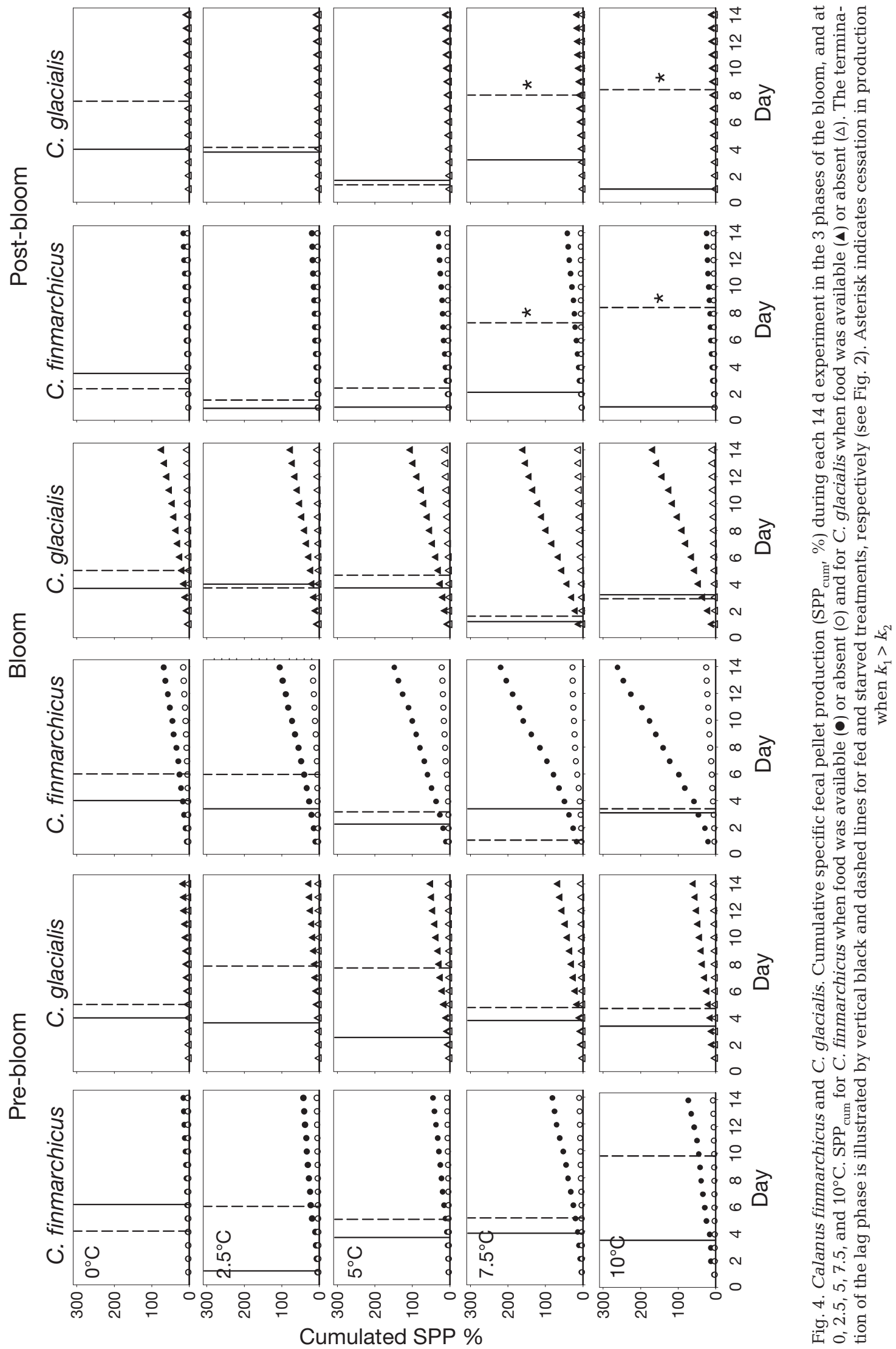




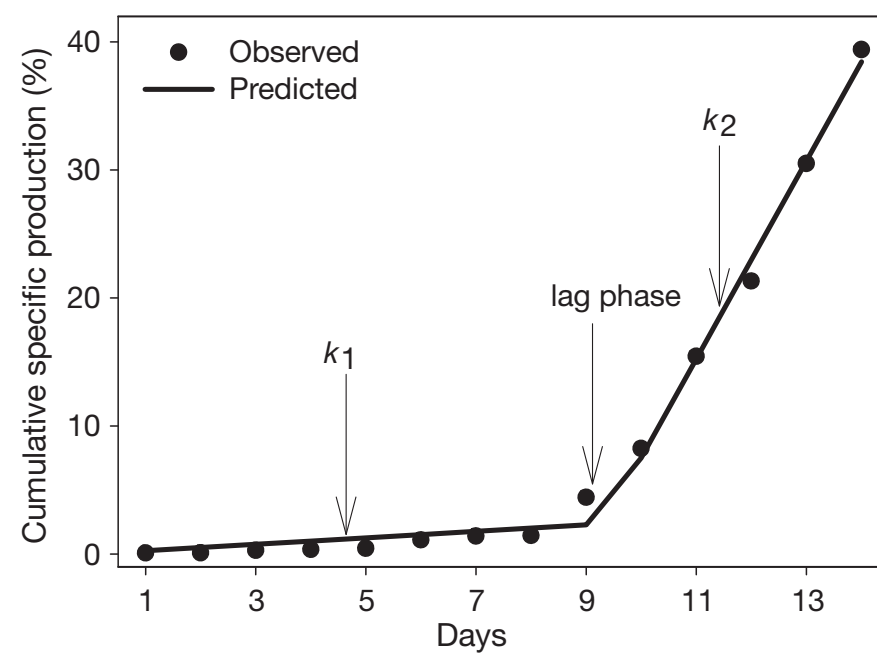

Fig. 5. Calanus finmarchicus and C. glacialis. Illustration of the model used to describe the cumulative specific production of fecal pellets and eggs. $k_{1}\left(\% \mathrm{C} \mathrm{d}^{-1}\right)$ is the slope of the line between $d_{0}$ until the termination of the lag phase $(l p)$, and $k_{2}\left(\% \mathrm{C} \mathrm{d}^{-1}\right)$ is the slope from the termination of the lag phase until $d_{14}$

Table 3. Calanus finmarchicus and C. glacialis. Mean size \pm SD and carbon content \pm SD of eggs. $n$ is no. of eggs measured

\begin{tabular}{|lcccc|}
\hline Species & $\mathrm{n}$ & $\begin{array}{c}\text { Diameter } \\
(\mu \mathrm{m})\end{array}$ & $\begin{array}{c}\text { Volume } \\
\left(10^{5} \mu \mathrm{m}^{3}\right)\end{array}$ & $\begin{array}{c}\text { Carbon } \\
\left(\mu \mathrm{egg}^{-1}\right)\end{array}$ \\
\hline C. finmarchicus & 1775 & $153 \pm 10$ & $19.0 \pm 4.0$ & $0.26 \pm 0.05$ \\
C. glacialis & 2883 & $178 \pm 12$ & $30.0 \pm 5.7$ & $0.41 \pm 0.08$ \\
\hline
\end{tabular}

phases were tested with a procedure for a general linear model (GLM, SAS Version 9.1, SAS Institute 2004) including both direct and combined effects of the independent variables. The most pronounced effects were found for food availability and temperature, but different patterns were observed for the response variable. For simplicity, we chose to apply the same model for all response variables and separately for the 2 species and the 3 phases. Differences between species and periods were analyzed by comparing the parameter estimates and their confidence limits. The model was:

$y=$ intercept $+\left(k_{\text {food }} \times\right.$ food $)+\left(k_{\text {temp }} \times\right.$ temp $)$

where $y$ is the rate for $\mathrm{SEP}_{\text {rate(k2) }}$ and $\mathrm{SPP}_{\text {rate(k2) }}$ and changes in carbon and content of lipids (total and different forms).The effect of Lugol's solution on the eggs and FP volume was tested using a $t$-test. A power function was chosen to describe the carbonlength relation based on a best fit analysis.

\section{RESULTS}

\section{Sampling conditions and species identification}

The in situ conditions on the dates when females for the experiments were collected are summarized in Table 4. More detailed descriptions of the oceanography and copepod biology are presented by Swalethorp et al. (2011) and Dünweber et al. (2010).

Only females fulfilling the pigmentation criteria were included in the experiments. The size and morphology (Calanus glacialis having a larger perivitelline space) of the eggs were inspected on several occasions during the experiment. The validity of these criteria (Fig. 2, Table 2) was confirmed by egg production of the 2 species incubated individually by Swalethorp et al. (2011).

\section{Effect of temperature and food availability on FP and egg volume}

Within the same treatment (temperature and food) in each period, no significant difference was detected for pellet and egg volumes on Day 3 or 4 ( $p>0.05)$. There were significant differences between the FP volume from the fed and starved treatment as well as between species $(\mathrm{p}<0.05$; Table $\mathrm{S} 1$ in the supplement at www.int-res.com/articles/suppl/m447 p087_supp.pdf). The effect of temperature on the FP volume was only significantly different between some temperatures, and the measured volume at each temperature was therefore applied for each temperature treatment (Table S1). No significant effects of food were detected on egg volumes within each species $(p>0.05)$. It was not possible to test the effect of temperature on the egg volume at intervals of $24 \mathrm{~h}$, as some eggs incubated at temperatures above $2.5^{\circ} \mathrm{C}$ were more developed or sometimes even hatched. The egg volume of the 2 species was significantly different $(p<0.05)$ when comparing 0 and $2.5^{\circ} \mathrm{C}$ treatments. This difference was confirmed by the egg volumes from a parallel in situ study (Swalethorp et al. 2011)

The carbon-length regressions were combined for the 2 species, as the residuals for the 2 species were not significantly different from a common power function. Carbon-length regressions were established for each of the 3 phases and for each treatment (initial, fed, and starved copepods) as the relationships were different for the 3 conditions (Table 5, Fig. S1). 
Table 4. Calanus finmarchicus and C. glacialis. In situ conditions on the 3 dates when females were collected for the experiments and spawning \%, specific egg production rate (SEP), specific fecal pellet production (SPP), egg production (EP), and fecal pellet production (FP)

\begin{tabular}{|c|c|c|c|}
\hline Date & $\begin{array}{l}\text { Pre-bloom } \\
22 \text { March }\end{array}$ & $\begin{array}{l}\text { Bloom } \\
22 \text { April }\end{array}$ & $\begin{array}{l}\text { Post-bloom } \\
28 \text { May }\end{array}$ \\
\hline \multirow{2}{*}{ 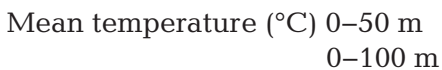 } & -1.3 & -1.3 & 0.5 \\
\hline & -0.3 & -0.8 & 0.7 \\
\hline Mean chl a 0-50 m $\left(\mu \mathrm{g} \mathrm{l}^{-1}\right)$ & 0.08 & 0.9 & 0.3 \\
\hline Chl a peak, $\mu g \mathrm{l}^{-1}$ (depth in $\mathrm{m}$ ) & $0.2(1)$ & $15.1(1)$ & $0.4(20)$ \\
\hline \multicolumn{4}{|l|}{ C. glacialis } \\
\hline Spawning \% & 5 & 55 & 22 \\
\hline $\operatorname{SEP}\left(\% d^{-1}\right)$ & $0.12 \pm 0.51$ & $1.74 \pm 2.17$ & $0.57 \pm 1.12$ \\
\hline $\operatorname{SPP}\left(\% d^{-1}\right)$ & $0.03 \pm 0.02$ & $0.44 \pm 0.26$ & $0.04 \pm 0.05$ \\
\hline$\%$ females in $0-50 \mathrm{~m}$ & 46 & 52 & 95 \\
\hline $\operatorname{EP}\left(\right.$ no. fem..$\left.^{-1} d^{-1}\right)$ & $0.7 \pm 2.9$ & $14.3 \pm 17.5$ & $6.6 \pm 13.2$ \\
\hline FP (no. fem..$^{-1} d^{-1}$ ) & $1.2 \pm 0.9$ & $17.0 \pm 8.1$ & $3.4 \pm 3.6$ \\
\hline \multicolumn{4}{|l|}{ C. finmarchicus } \\
\hline Spawning \% & 0 & 11 & 12 \\
\hline $\operatorname{SEP}\left(\% \mathrm{~d}^{-1}\right)$ & $0 \pm 0$ & $0.23 \pm 0.75$ & $0.08 \pm 0.26$ \\
\hline $\operatorname{SPP}\left(\% d^{-1}\right)$ & $0.01 \pm 0.01$ & $0.85 \pm 0.48$ & $0.27 \pm 0.28$ \\
\hline$\%$ females in $0-50 \mathrm{~m}$ & 31 & 50 & 86 \\
\hline $\operatorname{EP}\left(\right.$ no. fem..$\left.^{-1} \mathrm{~d}^{-1}\right)$ & $0 \pm 0$ & $1.2 \pm 4.1$ & $0.6 \pm 1.9$ \\
\hline FP (no. fem. ${ }^{-1} \mathrm{~d}^{-1}$ ) & $0.3 \pm 0.5$ & $20.7 \pm 9.3$ & $10.0 \pm 9.0$ \\
\hline
\end{tabular}

for unfed C. glacialis. Finally, when tested separately for each case $(2$ species $\times 2$ food treatments $\times 3$ periods $=$ 12 experiments), the lag phase was positively influenced by temperature in 2 of 12 cases (both for $C$. finmarchicus) and negatively influenced in the remaining cases, with 4 out of 12 being significant $(p<0.04)$.

\section{Effect of temperature and food concentration on $\mathrm{SEP}_{\text {rate(k2) }}$ and $\mathrm{SPP}_{\text {rate(k2) }}$}

The GLM (Eq. 3) always showed a positive effect of temperature on $\mathrm{SEP}_{\text {rate(k2), }}$ and the coefficient was significantly above 0 for both species in the pre-bloom and bloom periods when food was offered (Table 6). Moreover, the temperature response was significantly higher for Calanus finmarchicus than for C. glacialis. In

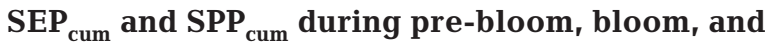 post-bloom}

From Figs. $3 \& 4$, it is evident that both food and temperature influenced the egg and FP production of both species (the raw data, i.e. mean egg and FP d $\mathrm{d}^{-1}$ in the different treatments after the lag phase, are shown in Table S2 in the supplement). All statistical analyses on eggs and FPs are based on data from Figs. 3 \& 4 after the lag phase using Eq. (2). The length of the lag phase was tested statistically and found to be negatively influenced by temperature for both species, but the effect was only significant for Calanus glacialis. When food is included as a parameter, the lag phase was still negatively influenced by temperature, but the effect was only significant the post-bloom period, temperature dependency was about 10 to 25 times lower and in most cases not significantly different from 0 . The intercepts were higher for C. glacialis than for C. finmarchicus in the pre-bloom and bloom, as was the coefficient for food availability, suggesting higher egg production of $C$. glacialis at near-0 temperatures, although the difference was not significant. However, combined with the higher positive coefficients of temperature, this gave the overall patterns observed in Fig. 6, that specific egg production was highest for C. glacialis at low temperature, whereas the opposite pattern was seen at higher temperatures.

Table 6 showed that $\mathrm{SPP}_{\text {rate(k2) }}$ increased with temperature when animals were fed, as seen for egg production (Fig. 6, Table 6). This effect was significant in

Table 5. Calanus finmarchicus and C. glacialis. Relationship between body weight (BW, mg C) and prosome length (PL, mm) in females of both species combined. The relationship for the initial samples, when food (the diatom Thalassiosira weissflogii) was available (food) and when food was absent (no food), at the 3 phases of the bloom. All temperatures are included. Each relationship is described by a power function where $\mathrm{BW}=a \times \mathrm{PL}^{b}$

\begin{tabular}{|lccc|}
\hline & Pre-bloom & Bloom & Post-bloom \\
\hline Initial & BW $(\mathrm{mg} \mathrm{C})=0.0008 \times \mathrm{PL}(\mathrm{mm})^{4.94}$ & $\mathrm{BW}(\mathrm{mg} \mathrm{C})=0.0010 \times \mathrm{PL}(\mathrm{mm})^{4.57}$ & $\mathrm{BW}(\mathrm{mg} \mathrm{C})=0.0048 \times \mathrm{PL}(\mathrm{mm})^{3.67}$ \\
& $\mathrm{r}^{2}=0.79(30)$ & $\mathrm{r}^{2}=0.78(30)$ & $\mathrm{r}^{2}=0.92(30)$ \\
Food & $\mathrm{BW}(\mathrm{mg} \mathrm{C})=0.0041 \times \mathrm{PL}(\mathrm{mm})^{3.52}$ & $\mathrm{BW}(\mathrm{mg} \mathrm{C})=0.0127 \times \mathrm{PL}(\mathrm{mm})^{2.40}$ & $\mathrm{BW}(\mathrm{mg} \mathrm{C})=0.0057 \times \mathrm{PL}(\mathrm{mm})^{3.33}$ \\
& $\mathrm{r}^{2}=0.84(54)$ & $\mathrm{r}^{2}=0.64(76)$ & $\mathrm{r}^{2}=0.73(69)$ \\
No food & $\mathrm{BW}(\mathrm{mg} \mathrm{C})=0.0015 \times \mathrm{PL}(\mathrm{mm})^{4.15}$ & $\mathrm{BW}(\mathrm{mg} \mathrm{C})=0.0005 \times \mathrm{PL}(\mathrm{mm})^{4.80}$ & $\mathrm{BW}(\mathrm{mg} \mathrm{C})=0.0009 \times \mathrm{PL}(\mathrm{mm})^{4.80}$ \\
& $\mathrm{r}^{2}=0.75(51)$ & $\mathrm{r}^{2}=0.78(81)$ & $\mathrm{r}^{2}=0.84(70)$ \\
\hline
\end{tabular}


Table 6. Calanus finmarchicus and C. glacialis. Effects of food availability and temperature on specific egg and specific fecal pellet production in the second phase $\left(k_{2}\right.$, Eq. 2$)$. Parameter values are given \pm SE and $\mathrm{p}$ levels are indicated $\left(\mathrm{p}>0.05[\mathrm{~ns}],{ }^{*} \mathrm{p}<0.05,{ }^{* *} \mathrm{p}<0.01\right.$,

$\left.{ }^{* * *} \mathrm{p}<0.001\right)$. Significant differences between species $(\mathrm{p}<0.05)$ are indicated in bold

\begin{tabular}{|c|c|c|c|c|c|c|c|}
\hline Intercept & $k_{\text {food }}$ & fooc & $k_{\text {temp }}$ & Intercept & $k_{\text {food }}$ & food & $k_{\text {temp }}$ \\
\hline \multicolumn{8}{|c|}{$k_{2 \text { egg }\left(\% \mathrm{~d}^{-1}\right)}=$ intercept $+\left(k_{\text {food }} \times\right.$ food $)+\left(k_{\text {temp }} \times\right.$ temp $)$, with and without food } \\
\hline \multicolumn{4}{|c|}{ C. finmarchicus - pre-bloom } & \multicolumn{4}{|c|}{ C. glacialis - pre-bloom } \\
\hline$-0.14 \pm 0.78(\mathrm{~ns})$ & $1.23 \pm 1.1(\mathrm{~ns})$ & $\begin{array}{l}1 \\
0\end{array}$ & $\begin{array}{l}\mathbf{0 . 9 3} \pm \mathbf{0 . 1 3}\left({ }^{(* * *}\right) \\
0.20 \pm 0.13(n s)\end{array}$ & $0.41 \pm 0.81(\mathrm{~ns})$ & $3.0 \pm 1.14\left(^{*}\right)$ & $\begin{array}{l}1 \\
0\end{array}$ & $\begin{array}{l}\mathbf{0 . 4 1} \pm \mathbf{0 . 1 3}\left(\mathbf{(}^{*}\right) \\
0.09 \pm 0.13(\mathrm{~ns})\end{array}$ \\
\hline \multicolumn{4}{|c|}{ C. finmarchicus - bloom } & \multicolumn{4}{|c|}{ C. glacialis - bloom } \\
\hline $0.07 \pm 1.68(\mathrm{~ns})$ & $-1.45 \pm 2.40(\mathrm{~ns})$ & $\begin{array}{l}1 \\
0\end{array}$ & $\begin{array}{l}\mathbf{1 . 4 1} \pm \mathbf{0 . 2 7}\left(\mathbf{(}^{* *}\right) \\
0.24 \pm 0.27(\mathrm{~ns})\end{array}$ & $1.03 \pm 0.43\left(^{*}\right)$ & $1.24 \pm 0.60(\mathrm{~ns})$ & $\begin{array}{l}1 \\
0\end{array}$ & $\begin{array}{l}\mathbf{0 . 5 9} \pm \mathbf{0 . 0 7}\left(\mathbf{(}^{* * *}\right) \\
0.05 \pm 0.07(n s)\end{array}$ \\
\hline \multicolumn{4}{|c|}{ C. finmarchicus - post-bloom } & \multicolumn{4}{|c|}{ C. glacialis - post-bloom } \\
\hline $0.49 \pm 0.12\left({ }^{* *}\right)$ & $0.20 \pm 0.17(\mathrm{~ns})$ & $\begin{array}{l}1 \\
0\end{array}$ & $\begin{array}{l}0.054 \pm 0.020(\mathrm{~ns}) \\
\left.0.028 \pm 0.020{ }^{*}\right)\end{array}$ & $0.49 \pm 0.16\left(^{*}\right)$ & $-0.10 \pm 0.23(\mathrm{~ns})$ & $\begin{array}{l}1 \\
0\end{array}$ & $\begin{array}{l}0.045 \pm 0.027(\mathrm{~ns}) \\
0.023 \pm 0.027(\mathrm{~ns})\end{array}$ \\
\hline \multicolumn{8}{|c|}{$k_{2 \text { pellet }\left(\% \mathrm{~d}^{-1}\right)}=$ intercept $+\left(k_{\text {food }} \times\right.$ food $)+\left(k_{\text {temp }} \times\right.$ temp $)$, with and without food } \\
\hline \multicolumn{4}{|c|}{ C. finmarchicus - pre-bloom } & \multicolumn{4}{|c|}{ C. glacialis - pre-bloom } \\
\hline $0.16 \pm 0.70(\mathrm{~ns})$ & $1.56 \pm 0.98(\mathrm{~ns})$ & $\begin{array}{l}1 \\
0\end{array}$ & $\begin{array}{l}0.46 \pm 0.11\left({ }^{* * *}\right) \\
0.07 \pm 0.11(\mathrm{~ns})\end{array}$ & $0.15 \pm 0.53(\mathrm{~ns})$ & $1.51 \pm 0.75(\mathrm{~ns})$ & $\begin{array}{l}1 \\
0\end{array}$ & $\begin{array}{l}0.39 \pm 0.09(\mathrm{~ns}) \\
0.02 \pm 0.09(\mathrm{~ns})\end{array}$ \\
\hline \multicolumn{4}{|c|}{ C. finmarchicus - bloom } & \multicolumn{4}{|c|}{ C. glacialis - bloom } \\
\hline $1.46 \pm 0.64(\mathrm{~ns})$ & $3.02 \pm 0.91\left(^{*}\right)$ & $\begin{array}{l}1 \\
0\end{array}$ & $\begin{array}{l}\mathbf{1 . 5 9} \pm \mathbf{0 . 1 1}\left({ }^{(* * *}\right) \\
0.05 \pm 0.11(\mathrm{~ns})\end{array}$ & $0.57 \pm 0.69(\mathrm{~ns})$ & $4.47 \pm 0.98\left({ }^{* *}\right)$ & $\begin{array}{l}1 \\
0\end{array}$ & $\begin{array}{l}\mathbf{0 . 7 7} \pm \mathbf{0 . 1 1}\left({ }^{* * *}\right) \\
0.04 \pm 0.11(\mathrm{~ns})\end{array}$ \\
\hline \multicolumn{4}{|c|}{ C. finmarchicus - post-bloom } & \multicolumn{4}{|c|}{ C. glacialis - post-bloom } \\
\hline $0.20 \pm 0.41(\mathrm{~ns})$ & $1.01 \pm 0.59(\mathrm{~ns})$ & $\begin{array}{l}1 \\
0\end{array}$ & $\begin{array}{r}0.11 \pm 0.07(\mathrm{~ns}) \\
-0.00 \pm 0.07(\mathrm{~ns})\end{array}$ & $0.08 \pm 0.16(\mathrm{~ns})$ & $0.48 \pm 0.23\left({ }^{*}\right)$ & $\begin{array}{l}1 \\
0\end{array}$ & $\begin{array}{r}0.04 \pm 0.03(\mathrm{~ns}) \\
-0.00 \pm 0.03(\mathrm{~ns})\end{array}$ \\
\hline
\end{tabular}

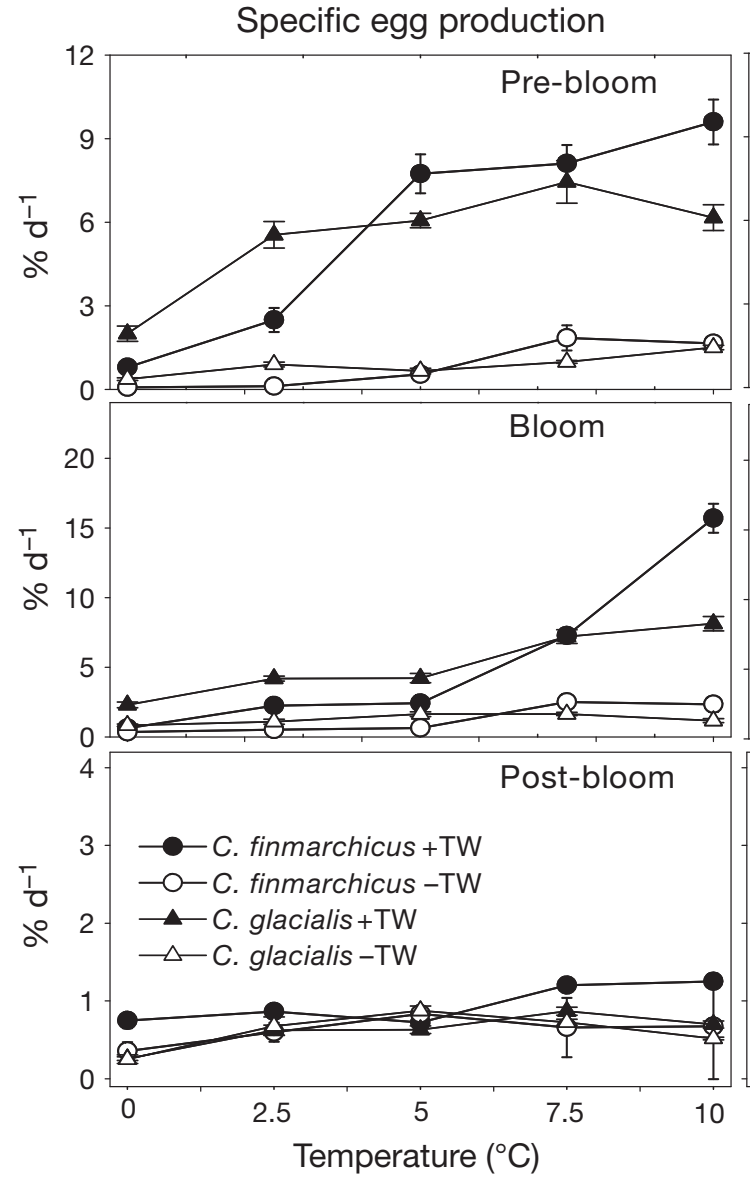

Specific egg production

Specific fecal pellet production

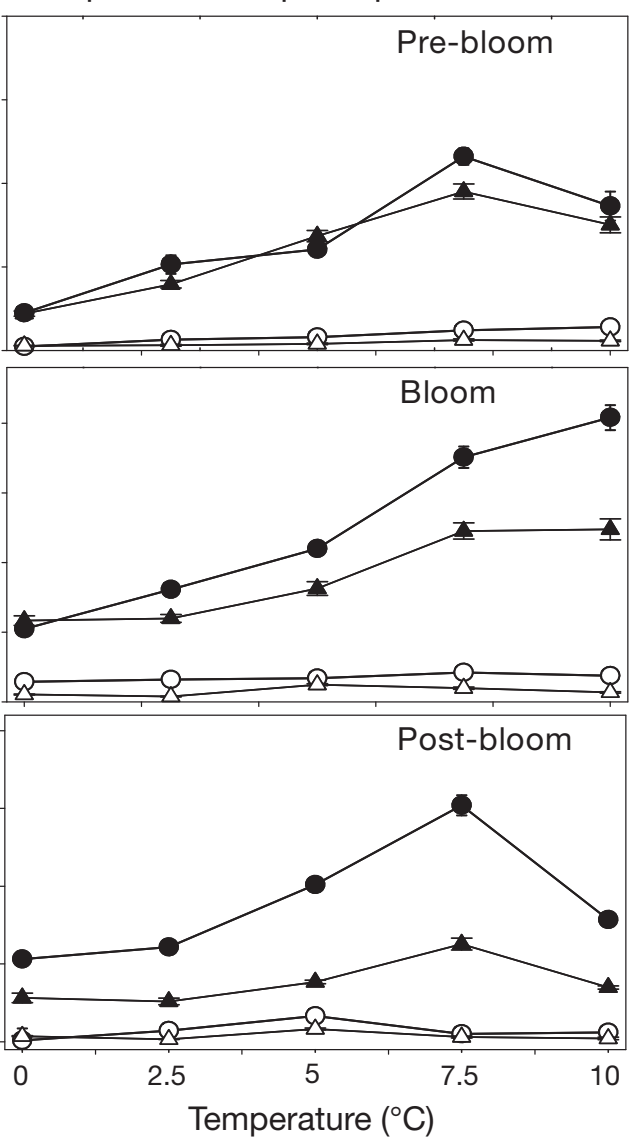

Fig. 6. Calanus finmarchicus and C. glacialis. Specific egg production $\left(\mathrm{SEP}_{\text {rate }(\mathrm{k} 2)}\right)$ and specific fecal pellet production $\left(\mathrm{SPP}_{\text {rate(k2) }}\right)$ in $\% \mathrm{~d}^{-1}$ at the 3 phases of the bloom based on production after the termination of the lag phase \pm SE. C. finmarchicus when food was available $(\bullet)$ or absent $(0)$ and C. glacialis when food was available ( $\mathbf{\Lambda})$ or absent $(\Delta)$. Note different $y$-axis scales 
the pre-bloom and bloom period for Calanus finmarchicus and in the bloom period for C. glacialis, and was significantly higher for $C$. finmarchicus. Food availability had similar positive effects on the pellet production for both species. However, the effect was only significant during the bloom period. For the starved copepods, the relationship to temperature was low and not significantly different from 0 in all phases of the bloom as well as for the fed copepods during post-bloom for both species. The intercept (pellet production at $0^{\circ} \mathrm{C}$ and no food) was always positive, indicating some production of ghost pellets (empty transparent fecal pellets; see Fig. 7a), but the values where never significantly above 0 .

\section{Effect of temperature and food on the carbon and lipid contents of the two Calanus species}

The initial carbon content differed substantially for Calanus finmarchicus and C. glacialis between the pre-bloom, bloom, and post-bloom experiments (Table 7). To be able to compare individuals and species independent of body size, carbon content was normalized to length based on the carbon-length regressions (Table 5).

The pattern from the GLM analysis was that the carbon loss during the experiment increased with increasing temperature for both species when the animals were starved (significantly in 5 out of 6 cases, Table 8). Food had a positive effect both on the overall level of carbon at the end of the experiment for both species. In 5 out of 6 cases, the coefficient for temperature was less negative compared to the experiments without food. The exception was $C$. glacialis in the post-bloom period, where the animals probably had stopped grazing. Before and during the bloom, grazing compensated for increasing temperature, so the coefficients for temperature was not significantly different from 0 .

TL $\left(\mu \mathrm{g} \mathrm{fem}^{-1}\right)^{-1}$ in the initial samples decreased between the pre-bloom and bloom, and then increased between the bloom and post-bloom for both species (Table 7). For C. finmarchicus, WE were the dominating lipid at the start of all experiments. During the development of the bloom, the initial values decreased from 97 to $77 \%$ of $\mathrm{TL}$, while PL became more predominant (Table 7 ). For C. glacialis, WE were also the dominating lipids at the initiation of the experiments in the pre-bloom and post-bloom, while PL were dominant during the bloom (Table 7). To be able to compare lipid reduction and gain between large and small indi- viduals and between species, lipid was normalized to carbon content.

In the GLM analysis, the TL content decreased in all 3 experiments without food (Table 9). Access to food had no clear effect except for Calanus glacialis in the bloom period where food caused a significant increase in the lipid content, probably due to resupplying of their lipid reserves. The loss rate of lipids was increasing with temperature for both species both with and without food in 10 out of 12 experiments, most conspicuous for C. finmarchicus where the temperature coefficients were significantly negative for the bloom and post-bloom period (Table 9).

The GLM analysis on the TAG content showed that Calanus finmarchicus accumulated large amounts of TAG, both compared to C. glacialis and compared to the changes for other types of lipids. However, TAG data had much higher variability compared to the other lipid classes, and only the effect of food was significant during the pre-bloom and bloom phase, indicating that the animals were actively feeding and starting to build up their TAG content. No clear patterns for temperature coefficients were observed (Table 9).

The GLM analysis also showed that Calanus finmarchicus was accumulating PL during the bloom and post-bloom phases showing positive intercepts and a strong response to food in the pre-bloom and bloom. In contrast, neither intercept nor response to food was significant for C. glacialis. Both species showed a tendency to higher losses with higher temperature, but the pattern was only significant for C. finmarchicus during the bloom period and postbloom (Table 9).

The pattern for WE resembled the pattern for TL (Table 9), and the GLM showed overall that animals were losing WE during the experiments. In all 3 experiments for Calanus finmarchicus and for $C$. glacialis in the pre-bloom and bloom, the intercept was significantly negative. The impact of food availability was not significantly different from 0 . The temperature coefficients were negative except for $C$. glacialis without food in the bloom experiment, although these were only significant in 3 cases (Table 9).

\section{DISCUSSION}

\section{Initiation of the phytoplankton bloom}

In a future warmer ocean, 3 potential scenarios could be envisioned for the initiation of the spring bloom: (1) An earlier phytoplankton bloom; if sea ice is present, it will melt earlier and strengthen the 
Table 7. Calanus finmarchicus and C. glacialis. Mean length $(\mathrm{mm})$, mean dry weight (DW, $\mu \mathrm{g})$, mean carbon weight $\left(\mu \mathrm{g} C\right.$ fem. $\left.{ }^{-1}\right)$, C:N ratio, and total lipid $\left(\mathrm{TL}, \mu \mathrm{g} \mathrm{fem} .{ }^{-1}\right) \pm \mathrm{SE}$ in each phase of the bloom and for each treatment. TL ( $\mu \mathrm{g}$ fem. ${ }^{-1}$ ), lipid content in percentage of carbon content, and percentage of triacylglycerol (TAG), phospholipid (PL), and wax ester (WE) of the TL content \pm SE. Sample size is shown in parentheses

\begin{tabular}{|c|c|c|c|c|c|c|c|c|c|c|}
\hline $\begin{array}{l}\text { Temp } \\
\left({ }^{\circ} \mathrm{C}\right)\end{array}$ & $\begin{array}{l}\text { Food } \\
(+/-)\end{array}$ & $\begin{array}{l}\text { Length } \\
(\mathrm{mm})\end{array}$ & $\begin{array}{c}\text { DW } \\
\left(\mu \mathrm{fem}^{-1}\right)\end{array}$ & $\begin{array}{c}\text { Carbon } \\
\left(\mu \mathrm{g} \mathrm{C} \text { fem. } .^{-1}\right)\end{array}$ & $\mathrm{C}: \mathrm{N}$ & $\begin{array}{c}\mathrm{TL} \\
\left(\mu \mathrm{g} \mathrm{fem} .^{-1}\right)\end{array}$ & $\begin{array}{c}\mathrm{TL} \\
(\% \mathrm{C})\end{array}$ & $\begin{array}{c}\text { TAG } \\
(\% \mathrm{TL})\end{array}$ & $\begin{array}{c}\text { PL } \\
(\% \mathrm{TL})\end{array}$ & $\begin{array}{c}\text { WE } \\
(\% \mathrm{TL})\end{array}$ \\
\hline \multicolumn{11}{|c|}{ C. finmarchicus - pre-bloom } \\
\hline Initial & & $2.70 \pm 0.03(15)$ & $253 \pm 23(15)$ & $135 \pm 16(15)$ & 7.1 & $73 \pm 7(10)$ & $54 \pm 5(10)$ & $0.2 \pm 0.03(10)$ & $3.0 \pm 0.5(10)$ & $96.9 \pm 0.5(10)$ \\
\hline 0 & + & $2.77 \pm 0.03(19)$ & $319 \pm 21(7)$ & $151 \pm 13(7)$ & 5.5 & $45 \pm 4(3)$ & $29 \pm 2(3)$ & $1.4 \pm 0.3(3)$ & $14.4 \pm 2.5(3)$ & $84.3 \pm 2.3(3)$ \\
\hline 0 & - & $2.74 \pm 0.04(18)$ & $327 \pm 49(6)$ & $149 \pm 32(6)$ & 6.9 & $51 \pm 10(3)$ & $49 \pm 8(3)$ & $0.1 \pm 0.1(3)$ & $3.4 \pm 0.5(3)$ & $96.5 \pm 0.5(3)$ \\
\hline 2.5 & + & $2.62 \pm 0.03(24)$ & $266 \pm 18(7)$ & $113 \pm 6(7)$ & 4.3 & $39 \pm 2(4)$ & $30 \pm 2(4)$ & $12.3 \pm 4.5(4)$ & $36.7 \pm 3.4(4)$ & $50.9 \pm 5.3(4)$ \\
\hline 2.5 & - & $2.66 \pm 0.03(23)$ & $209 \pm 10(7)$ & $88 \pm 5(7)$ & 4.3 & $17 \pm 2(4)$ & $19 \pm 1(4)$ & $1.0 \pm 0.1$ & $7.5 \pm 2.9$ & $91.5 \pm 2.8$ \\
\hline 5 & + & $2.68 \pm 0.03(18)$ & $497 \pm 76$ & $171 \pm 18$ & 4.2 & $42 \pm 2(2)$ & $31 \pm 2(2)$ & $7.5 \pm 4.5(2)$ & $26.0 \pm 7.2(2)$ & $66.5 \pm 11.7(2)$ \\
\hline 5 & - & $2.73 \pm 0.03(20)$ & $377 \pm 33(8)$ & $114 \pm 10$ & 5.6 & $43 \pm 11(3)$ & $40 \pm 9(3)$ & $0.3 \pm 0.1$ & $7.5 \pm 1.2$ & $92.2 \pm 1.3$ \\
\hline 7.5 & + & $2.68 \pm 0.02(19)$ & $251 \pm 15(7)$ & $117 \pm 9(7)$ & 4.4 & $27 \pm 18(2)$ & $21 \pm 14(2)$ & $17.9 \pm 5.9(2)$ & $47.0 \pm 15.9$ & $35.1 \pm 21.8(2)$ \\
\hline 7.5 & - & $2.72 \pm 0.03(16)$ & $215 \pm 13(4)$ & $88 \pm 8(4)$ & 4.6 & $30 \pm 10(3)$ & $29 \pm 9(3)$ & $1.4 \pm 0.5$ & $7.5 \pm 1.2(3)$ & $91.1 \pm 2.3$ \\
\hline 10 & + & $2.71 \pm 0.03(18)$ & $296 \pm 19$ & $126 \pm 11$ & 4.1 & $25 \pm 8(3)$ & $18 \pm 6(3)$ & $10.8 \pm 1.0$ & $54.3 \pm 14.0$ & $34.8 \pm 15.1$ \\
\hline 10 & - & $2.67 \pm 0.03(12)$ & $184 \pm 35$ & $76 \pm 18$ & 5.1 & $28 \pm 3(2)$ & $32 \pm 2(2)$ & $0.5 \pm 0.4(2)$ & $3.9 \pm 2.5(2)$ & $95.6 \pm 2.1(2)$ \\
\hline \multicolumn{11}{|c|}{ C. finmarchicus - bloom } \\
\hline Initial & & $2.65 \pm 0.04(16)$ & $236 \pm 20(15)$ & $109 \pm 6(15)$ & 5.2 & $45 \pm 7(10)$ & $41 \pm 6(10)$ & $0.2 \pm 0.1(10)$ & $11.4 \pm 1.4(10)$ & $88.3 \pm 1.4(10)$ \\
\hline 0 & + & $2.73 \pm 0.03(30)$ & $397 \pm 32(10)$ & $148 \pm 17(10)$ & 4.6 & $31 \pm 3(4)$ & $22 \pm 2(4)$ & $10.0 \pm 4.1(4)$ & $46.1 \pm 6.3(4)$ & $43.9 \pm 10.1(4)$ \\
\hline 0 & - & $2.70 \pm 0.03(29)$ & $187 \pm 12(8)$ & $66 \pm 7(8)$ & 4.2 & $12 \pm 4(4)$ & $18 \pm 6(4)$ & $2.8 \pm 1.0$ & $49.8 \pm 9.8(4)$ & $47.3 \pm 10.8(4)$ \\
\hline 2.5 & + & $2.68 \pm 0.03(29)$ & $313 \pm 22(9)$ & $136 \pm 11(9)$ & 4.3 & $26 \pm 4(4)$ & $19 \pm 2(4)$ & $21.3 \pm 3.3(4)$ & $52.7 \pm 3.6(4)$ & $26.0 \pm 6.9(4)$ \\
\hline 2.5 & - & $2.69 \pm 0.02(30)$ & $321 \pm 10(9)$ & $77 \pm 8(9)$ & 3.9 & $9 \pm 2(4)$ & $14 \pm 4(4)$ & $3.4 \pm 1.2(4)$ & $41.8 \pm 6.3(4)$ & $54.8 \pm 6.6(4)$ \\
\hline 5 & + & $2.70 \pm 0.02(29)$ & $328 \pm 24(9)$ & $134 \pm 17(9)$ & 4.1 & $29 \pm 6(4)$ & $21 \pm 5(4)$ & $20.7 \pm 6.6$ & $50.4 \pm 10.5(4)$ & $28.9 \pm 15.7$ \\
\hline 5 & - & $2.73 \pm 0.03(29)$ & $321 \pm 10$ & $72 \pm 6(9)$ & 3.7 & $6 \pm 1(4)$ & $10 \pm 1(4)$ & $6.8 \pm 2.9(4)$ & $38.4 \pm 9.1(4)$ & $54.8 \pm 6.6(4)$ \\
\hline 7.5 & + & $2.75 \pm 0.03(27)$ & $209 \pm 16$ & $130 \pm 14(6)$ & 3.8 & $21 \pm 4(4)$ & $14 \pm 2(4)$ & $15.3 \pm 4.0$ & $66.2 \pm 10.7$ & $18.5 \pm 8.3$ \\
\hline 7.5 & - & $2.76 \pm 0.03(29)$ & $174 \pm 28(9)$ & $63 \pm 5(9)$ & 3.5 & $4 \pm 3(2)$ & $6 \pm 4(2)$ & $22.9 \pm 2.4(2)$ & $52.6 \pm 25.9(2)$ & $24.5 \pm 23.5(2)$ \\
\hline 10 & + & $2.68 \pm 0.03(27)$ & $290 \pm 26(7)$ & $127 \pm 13(7)$ & 3.8 & $14 \pm 2(4)$ & $10 \pm 1(4)$ & $14.1 \pm 4.0$ & $67.3 \pm 6.7(4)$ & $18.6 \pm 10.3$ \\
\hline 10 & - & $2.67 \pm 0.03(29)$ & $160 \pm 17(8)$ & $51 \pm 4(8)$ & 3.3 & $2 \pm 2(2)$ & $3 \pm 3(2)$ & $11.3 \pm 4.6(2)$ & $26.9 \pm 12.2(2)$ & $61.8 \pm 16.8$ \\
\hline \multicolumn{11}{|c|}{ C. finmarchicus - post-bloom } \\
\hline Initial & & $2.75 \pm 0.03(14)$ & $279 \pm 25(14)$ & $181 \pm 14(15)$ & 5.2 & $56 \pm 5(10)$ & $31 \pm 3(10)$ & $7.3 \pm 1.0(10)$ & $16.2 \pm 2.0(10)$ & $76.6 \pm 2.5(10)$ \\
\hline 0 & + & $2.74 \pm 0.02(28)$ & $309 \pm 33(7)$ & $154 \pm 20(7)$ & 5.3 & $26 \pm 3(4)$ & $15 \pm 1(4)$ & $23.6 \pm 3.5(4)$ & $41.6 \pm 6.4(4)$ & $34.8 \pm 7.6(4)$ \\
\hline 0 & - & $2.74 \pm 0.02(30)$ & $324 \pm 41(7)$ & $124 \pm 20(7)$ & 4.3 & $19 \pm 4(4)$ & $16 \pm 3(4)$ & $14.9 \pm 1.7(4)$ & $47.2 \pm 6.5(4)$ & $37.9 \pm 8.0(4)$ \\
\hline 2.5 & + & $2.80 \pm 0.03(31)$ & $399 \pm 51(7)$ & $145 \pm 15(7)$ & 4.0 & $31 \pm 2(4)$ & $16 \pm 2(4)$ & $19.4 \pm 5.6(4)$ & $44.0 \pm 3.7(4)$ & $36.6 \pm 6.1(4)$ \\
\hline 2.5 & - & $2.71 \pm 0.03$ & $238 \pm 33(7)$ & $87 \pm 12(7)$ & 3.7 & $18 \pm 3(4)$ & $16 \pm 2(4)$ & $17.0 \pm 5.2$ & $46.6 \pm 6.7$ & $36.4 \pm 2.8$ \\
\hline 5 & + & $2.79 \pm 0.03(31)$ & $359 \pm 35(7)$ & $152 \pm 15(7)$ & 4.2 & $22 \pm 1(4)$ & $12 \pm 1(4)$ & $28.2 \pm 5.2(4)$ & $56.0 \pm 4.5(4)$ & $15.8 \pm 9.2(4)$ \\
\hline 5 & - & $2.74 \pm 0.03(29)$ & $283 \pm 34(7)$ & $114 \pm 19(7)$ & 4.2 & $12 \pm 2(4)$ & $10 \pm 2(4)$ & $11.9 \pm 2.4$ & $48.0 \pm 9.0(4)$ & $40.1 \pm 10.6$ \\
\hline 7.5 & + & $2.75 \pm 0.03(29)$ & $382 \pm 41(7)$ & $152 \pm 24(7)$ & 5.1 & $26 \pm 3(4)$ & $16 \pm 1(4)$ & $18.6 \pm 5.5(4)$ & $42.1 \pm 3.7(4)$ & $39.3 \pm 8.8$ \\
\hline 7.5 & - & $2.70 \pm 0.03(28)$ & $192 \pm 15(7)$ & $70 \pm 5(7)$ & 3.9 & $11 \pm 4(4)$ & $9 \pm 2(4)$ & $20.6 \pm 10.8$ & $45.0 \pm 8.3$ & $34.4 \pm 15.9$ \\
\hline 10 & + & $2.74 \pm 0.02(32)$ & $284 \pm 48(7)$ & $88 \pm 12(7)$ & 3.7 & $9 \pm 1(4)$ & $5 \pm 1(4)$ & $27.3 \pm 3.0$ & $69.9 \pm 1.5$ & $2.8 \pm 2.3$ \\
\hline 10 & - & $2.76 \pm 0.03$ & $183 \pm 24(7)$ & $67 \pm 6(7)$ & 3.5 & $7 \pm 2(4)$ & $5 \pm 1(4)$ & $14.5 \pm 3.3$ & $67.2 \pm 1(4)$ & $18.3 \pm 11.6(4)$ \\
\hline
\end{tabular}

water column stratification, triggering an early bloom (Smith 1987, Wu et al. 2007, Kahru et al. 2011); (2) An unchanged timing of the bloom, in a warmer ocean with less or no sea ice; and (3) A prolonged spring bloom period controlled by nitrate supply (Tremblay \& Gagnon 2009), since weak stratification and impact of wind may allow higher exchange between the deeper nutrient-rich water and the relatively nutrient-poor water in the photic zone. Based on our experiments, we discuss the potential implications of the 3 scenarios for the coexistence and competition of Calanus finmarchicus and C. glacialis females.

Changes in the environment will change the selective pressures on the Calanus populations and prob- ably induce adaptations that will affect their life cycle, such as the timing of diapause as suggested for North Atlantic C. finmarchicus populations (Johnson et al. 2008, Maps et al. 2010). Such selectionmediated changes may co-occur with the responses predicted in the present study; however, they are not considered further here.

\section{Scenario 1: Early spring phytoplankton bloom}

We mimicked an early bloom by offering the copepods collected in mid-March unlimited food in combination with increasing temperatures. The potential 
Table 7 (continued)

\begin{tabular}{|c|c|c|c|c|c|c|c|c|c|c|}
\hline $\begin{array}{l}\text { Temp } \\
\left({ }^{\circ} \mathrm{C}\right)\end{array}$ & $\begin{array}{l}\text { Food } \\
(+/-)\end{array}$ & $\begin{array}{l}\text { Length } \\
\text { (mm) }\end{array}$ & $\begin{array}{c}\text { DW } \\
\left(\mu \mathrm{fem}^{-1}\right)\end{array}$ & $\begin{array}{c}\text { Carbon } \\
\left(\mu \mathrm{g} C \text { fem. }^{-1}\right)\end{array}$ & $\mathrm{C}: \mathrm{N}$ & $\begin{array}{c}\mathrm{TL} \\
\left(\mu \mathrm{g} \mathrm{fem} \cdot{ }^{-1}\right)\end{array}$ & $\begin{array}{c}\text { TL } \\
(\% \mathrm{C})\end{array}$ & $\begin{array}{c}\text { TAG } \\
(\% \mathrm{TL})\end{array}$ & $\begin{array}{c}\mathrm{PL} \\
(\% \mathrm{TL})\end{array}$ & $\begin{array}{c}\text { WE } \\
(\% \mathrm{TL})\end{array}$ \\
\hline \multicolumn{11}{|c|}{ C. glacialis - pre-bloom } \\
\hline Initial & & $3.36 \pm 0.07(15)$ & $620 \pm 65(15)$ & $332 \pm 42(15)$ & 6.9 & $198 \pm 30(10)$ & $60 \pm 9(10)$ & $0.6 \pm 0.2(10)$ & $7.1 \pm 0.8(10)$ & $92.3 \pm 0.8(10)$ \\
\hline 0 & + & $3.45 \pm 0.06(14)$ & $653 \pm 79(6)$ & $282 \pm 41(6)$ & 5.4 & $181 \pm 26(4)$ & $48 \pm 6(4)$ & $3.1 \pm 1(4)$ & $16.1 \pm 0.6(4)$ & $80.8 \pm 1.3(4)$ \\
\hline 0 & - & $3.38 \pm 0.06(14)$ & $667 \pm 13(6)$ & $275 \pm 78(6)$ & 5.7 & $70 \pm 28(4)$ & $28 \pm 9(4)$ & $2.3 \pm 0.9(4)$ & $25.3 \pm 11.2(4)$ & $72.4 \pm 11.6(4)$ \\
\hline 2.5 & + & $3.30 \pm 0.08(10)$ & $662 \pm 15(4)$ & $272 \pm 78(4)$ & 4.8 & $68 \pm 14(3)$ & $25 \pm 3(3)$ & $8.1 \pm 2.9(3)$ & $19.9 \pm 6.8$ & $72.0 \pm 9.4$ \\
\hline 2.5 & - & $3.38 \pm 0.06(10)$ & $533 \pm 10(4)$ & $215 \pm 48$ & 4.7 & $161 \pm 40(3)$ & $63 \pm 17(3)$ & $1 \pm 0.1$ & $15.1 \pm 4.1(3)$ & $83.9 \pm 4.1(3)$ \\
\hline 5 & + & $3.49 \pm 0.07$ & $759 \pm 15$ & $308 \pm 60(5)$ & 4.6 & $85 \pm 21(4)$ & $24 \pm 6(4)$ & $12 \pm 2.8$ & $42.2 \pm 9.1(4)$ & $45.8 \pm 11.1$ \\
\hline 5 & - & $3.73 \pm 0.09(6)$ & $971 \pm 1(2)$ & $515 \pm 10(2)$ & 7.7 & - & - & - & - & - \\
\hline 7.5 & + & $3.50 \pm 0.09$ & $670 \pm 11(5)$ & $303 \pm 66(5)$ & 4.9 & $79 \pm 11(3)$ & $21 \pm 3(3)$ & $4.3 \pm 1.9(3)$ & $29.8 \pm 3.2(3)$ & $65.9 \pm 2.3(3)$ \\
\hline 7.5 & - & $3.53 \pm 0.07$ & $608 \pm 70$ & $269 \pm 36(5)$ & 5.2 & $57 \pm 14(4)$ & $21 \pm 4(4)$ & $2.3 \pm 1.6(4)$ & $27.0 \pm 17.2(4)$ & $70.8 \pm 16.7(4)$ \\
\hline 10 & + & $3.37 \pm 0.06(14)$ & $610 \pm 51(6)$ & $284 \pm 28(6)$ & 4.7 & $53 \pm 16(4)$ & $16 \pm 4(4)$ & $11.9 \pm 2.6$ & $38.3 \pm 7.8(4)$ & $49.8 \pm 8.2(4)$ \\
\hline 10 & - & $3.26 \pm 0.06(14)$ & $391 \pm 72(5)$ & $161 \pm 41$ & 4.6 & $76 \pm 26$ & $39 \pm 12(4)$ & $11.1 \pm 7.8$ & $12.5 \pm 4.3$ & $76.4 \pm 10.1$ \\
\hline \multicolumn{11}{|c|}{ C. glacialis - bloom } \\
\hline Initial & & $3.44 \pm 0.07(15)$ & $588 \pm 61(15)$ & $287 \pm 39(15)$ & 5.5 & $43 \pm 15(6)$ & $15 \pm 5(6)$ & $2.5 \pm 0.4(6)$ & $49.2 \pm 12.1(6)$ & $48.5 \pm 12.3(6)$ \\
\hline 0 & + & $3.36 \pm 0.06(19)$ & $625 \pm 42(7)$ & $246 \pm 17(7)$ & 4.0 & $57 \pm 15(3)$ & $24 \pm 6(3)$ & $18.7 \pm 6.2(3)$ & $57.0 \pm 12.6(3)$ & $24.3 \pm 18.2(3)$ \\
\hline 0 & - & $3.50 \pm 0.06(20)$ & $570 \pm 62(8)$ & $223 \pm 39(8)$ & 4.3 & $32 \pm 6(4)$ & $15 \pm 3(4)$ & $4.9 \pm 1.8(4)$ & $49.7 \pm 13.4(4)$ & $45.3 \pm 15.0(4)$ \\
\hline 2.5 & + & $3.40 \pm 0.06(20)$ & $602 \pm 26(8)$ & $269 \pm 13(8)$ & 4.6 & $67 \pm 26(4)$ & $26 \pm 9(4)$ & $7.2 \pm 3(4)$ & $51.7 \pm 15.0(4)$ & $41.0 \pm 15.6(4)$ \\
\hline 2.5 & - & $3.40 \pm 0.05(19)$ & $527 \pm 58(7)$ & $214 \pm 38(7)$ & 4.8 & $20 \pm 4(4)$ & $12 \pm 3(4)$ & $2.8 \pm 1.2(4)$ & $63.9 \pm 17.1(4)$ & $33.3 \pm 16.6(4)$ \\
\hline 5 & + & $3.37 \pm 0.06(20)$ & $499 \pm 28$ & $210 \pm 13$ & 4.1 & $88 \pm 23(4)$ & $34 \pm 7(4)$ & $14.4 \pm 5.3$ & $34.0 \pm 6.7(4)$ & $51.6 \pm 11.4$ \\
\hline 5 & - & $3.40 \pm 0.06$ & $408 \pm 28(7)$ & $143 \pm 13(7)$ & 3.7 & $26 \pm 5(4)$ & $13 \pm 2(4)$ & $5.4 \pm 3.3$ & $44.7 \pm 11.7$ & $49.8 \pm 14.5$ \\
\hline 7.5 & + & $3.40 \pm 0.05$ (19) & $531 \pm 34(7)$ & $214 \pm 18(7)$ & 4.0 & $41 \pm 6(4)$ & $17 \pm 2(4)$ & $22.2 \pm 2.3$ & $60.2 \pm 4.3(4)$ & $17.7 \pm 5.1$ \\
\hline 7.5 & - & $3.44 \pm 0.5(20)$ & $371 \pm 31$ & $135 \pm 20$ & 3.8 & $34 \pm 14(4)$ & $16 \pm 6(4)$ & $5.1 \pm 2.1$ & $55.3 \pm 18.9(4)$ & $39.6 \pm 19.6(4)$ \\
\hline 10 & + & $3.19 \pm 0.08(17)$ & $525 \pm 62$ & $224 \pm 31$ & 4.3 & $49 \pm 9(4)$ & $26 \pm 7(4)$ & $10.6 \pm 2.6$ & $41.9 \pm 7.9(4)$ & $47.5 \pm 8.2(4)$ \\
\hline 10 & - & $3.32 \pm 0.05(20)$ & $322 \pm 37(8)$ & $113 \pm 14$ & 3.5 & $24 \pm 8(4)$ & $13 \pm 3(4)$ & $2.7 \pm 1.2$ & $43.4 \pm 18.0$ & $53.9 \pm 18.2(4)$ \\
\hline \multicolumn{11}{|c|}{ C. glacialis - post-bloom } \\
\hline Initial & & $3.46 \pm 0.09(15)$ & $856 \pm 63(15)$ & $487 \pm 38(15)$ & 7.7 & $306 \pm 27(8)$ & $63 \pm 6(8)$ & $5.6 \pm 1.2(8)$ & $8.6 \pm 0.6(8)$ & $85.7 \pm 1.2(8)$ \\
\hline 0 & + & $3.56 \pm 0.07(20)$ & $800 \pm 52(7)$ & $429 \pm 18(7)$ & 7.0 & $247 \pm 49(4)$ & $59 \pm 6(4)$ & $2.9 \pm 1(4)$ & $8.5 \pm 2.5(4)$ & $88.6 \pm 2.8(4)$ \\
\hline 0 & - & $3.51 \pm 0.05(20)$ & $705 \pm 68(7)$ & $372 \pm 50(7)$ & 7.0 & $235 \pm 44(4)$ & $107 \pm 15(4)$ & $2.8 \pm 0.6(4)$ & $7.8 \pm 1.9(4)$ & $89.3 \pm 2.4(4)$ \\
\hline 2.5 & + & $3.52 \pm 0.06(20)$ & $903 \pm 80(6)$ & $497 \pm 56(6)$ & 7.3 & $217 \pm 19(3)$ & $59 \pm 4(3)$ & $3.1 \pm 0.9$ & $9.8 \pm 2.3$ & $87.1 \pm 2.3$ \\
\hline 2.5 & - & $3.52 \pm 0.06$ & $900 \pm 51(7)$ & $472 \pm 39(7)$ & 7.3 & $290 \pm 19$ & $74 \pm 1(3)$ & $1.7 \pm 0.3$ & $8.4 \pm 1.4$ & $89.9 \pm 1.6(3)$ \\
\hline 5 & + & $3.58 \pm 0.06(20)$ & $884 \pm 95(7)$ & $472 \pm 53(7)$ & 7.3 & $180 \pm 34(4)$ & $44 \pm 6(4)$ & $6.8 \pm 2.2(4)$ & $10.5 \pm 2.5$ & $82.7 \pm 4.6(4)$ \\
\hline 5 & - & $3.62 \pm 0.06(20)$ & $863 \pm 110(7)$ & $461 \pm 59(7)$ & 7.4 & $218 \pm 19(4)$ & $50 \pm 5(4)$ & $4.5 \pm 1.5(4)$ & $8.9 \pm 2.4$ & $86.6 \pm 3.8(4)$ \\
\hline 7.5 & + & $3.59 \pm 0.06(19)$ & $821 \pm 72(7)$ & $425 \pm 44(7)$ & 6.8 & $198 \pm 43(4)$ & $49 \pm 9(4)$ & $3 \pm 0.6(4)$ & $11.2 \pm 2.4(4)$ & $85.8 \pm 2.2(4)$ \\
\hline 7.5 & - & $3.54 \pm 0.07(20)$ & $736 \pm 99(7)$ & $401 \pm 66(7)$ & 7.6 & $192 \pm 61(4)$ & $42 \pm 11(4)$ & $2 \pm 0.8$ & $9.2 \pm 1.5$ & $88.8 \pm 2.1(4)$ \\
\hline 10 & + & $3.46 \pm 0.07$ (19) & $674 \pm 49(7)$ & $320 \pm 30(7)$ & 6.2 & $177 \pm 18(4)$ & $51 \pm 4(4)$ & $5.5 \pm 3.9(4)$ & $6.6 \pm 2.3(4)$ & $88.0 \pm 3.9(4)$ \\
\hline 10 & - & $3.67 \pm 0.05$ (19) & $791 \pm 11(7)$ & $399 \pm 79(7)$ & 7.2 & $233 \pm 37$ & $49 \pm 5(4)$ & $2.6 \pm 1.1$ & $8.3 \pm 1.6(4)$ & $89.5 \pm 2.1$ \\
\hline
\end{tabular}

specific egg production responded almost linearly to temperature by a factor of 12 for Calanus finmarchicus between 0 and $10^{\circ} \mathrm{C}$ and by a factor of 3.7 for $C$. glacialis between 0 and $7.5^{\circ} \mathrm{C}$ (Fig. 6). At all temperatures during the pre-bloom as well as during the bloom experiment, the carbon-specific egg production for C. glacialis was within the previously observed range from a study in the Greenland Sea and the Arctic Ocean (Hirche \& Kosobokova 2007). The specific egg production for C. finmarchicus was similar to that reported by Runge (1985) at all temperatures as well as that reported by Plourde \& Runge (1993) at $7.5^{\circ} \mathrm{C}$. However, values were lower than those reported by Hirche et al. (1997) in the Norwegian Sea. SPP was similar for the 2 Calanus species at all temperatures during the pre-bloom, which indicates equal feeding rates. During and after the bloom, C. finmarchicus was grazing at a higher rate than C. glacialis (Fig. 6). The increase in grazing rate between the pre-bloom and the bloom experiment was about 3-fold for $C$. finmarchicus and 2-fold for C. glacialis (Fig. 6), indicating that both species are less efficient or not ready to exploit the food early in the season.

The ratio between grazed material and the quantity allocated to egg production was almost constant for Calanus glacialis at all temperatures, whereas the energy allocated for egg production increased with temperature for $C$. finmarchicus. Maximal egg pro- 
Table 8. Calanus finmarchicus and C. glacialis. Effects of food availability and temperature on carbon content ( $\mu g$ C) normalized to length $(\mu \mathrm{m})$ for the 2 species tested for the 3 periods. $\operatorname{Ln}\left(\mu \mathrm{g} \mathrm{C} \mu \mathrm{m}^{-1}\right)=$ intercept $+k_{\mathrm{food}} \times$ food $+k_{\mathrm{temp}} \times$ temp (with and without food). Parameter values are given $\pm \mathrm{SE}$ and $\mathrm{p}$ levels are indicated $\left(\mathrm{p}>0.05[\mathrm{~ns}],{ }^{*} \mathrm{p}<0.05,{ }^{* *} \mathrm{p}<0.01,{ }^{* * *} \mathrm{p}<0.001\right)$. Significant differences between species $(\mathrm{p}<0.05)$ are indicated in bold

\begin{tabular}{|c|c|c|c|c|c|c|c|}
\hline Intercept & $k_{\text {food }}$ & fooc & $k_{\text {temp }}$ & Intercept & $k_{\text {food }}$ & food & $k_{\text {temp }}$ \\
\hline \multicolumn{4}{|c|}{ C. finmarchicus - pre-bloom } & \multicolumn{4}{|c|}{ C. glacialis - pre-bloom } \\
\hline $0.86 \pm 1.2(\mathrm{~ns})$ & $1.7 \pm 1.6(\mathrm{~ns})$ & $\begin{array}{l}1 \\
0\end{array}$ & $\begin{array}{l}-0.37 \pm 0.38(\mathrm{~ns}) \\
-1.41 \pm 0.31\left({ }^{* *}\right)\end{array}$ & $-2.0 \pm 1.7(\mathrm{~ns})$ & $-1.7 \pm 2.2(\mathrm{~ns})$ & $\begin{array}{l}1 \\
0\end{array}$ & $\begin{array}{r}0.27 \pm 0.50(\mathrm{~ns}) \\
-0.87 \pm 0.39(\mathrm{~ns})\end{array}$ \\
\hline \multicolumn{4}{|c|}{ C. finmarchicus - bloom } & \multicolumn{4}{|c|}{ C. glacialis - bloom } \\
\hline$-0.8 \pm 1.1\left({ }^{* *}\right)$ & $3.4 \pm 1.5\left(^{* * *}\right)$ & $\begin{array}{l}1 \\
0\end{array}$ & $\begin{array}{l}0.06 \pm 0.34(\mathrm{~ns}) \\
-2.1 \pm 0.25\left(^{* *}\right)\end{array}$ & $-1.5 \pm 1.1(\mathrm{~ns})$ & $0.2 \pm 1.5(\mathrm{~ns})$ & $\begin{array}{l}1 \\
0\end{array}$ & $\begin{aligned}-0.23 & \pm 0.35(\mathrm{~ns}) \\
-1.8 & \pm 0.2\left({ }^{* *}\right)\end{aligned}$ \\
\hline \multicolumn{4}{|c|}{ C. finmarchicus - post-bloom } & \multicolumn{4}{|c|}{ C. glacialis - post-bloom } \\
\hline$-4.1 \pm 1.3\left({ }^{* *}\right)$ & $-0.9 \pm 1.7(\mathrm{~ns})$ & $\begin{array}{l}1 \\
0\end{array}$ & $\begin{array}{l}-0.65 \pm 0.38(\mathrm{~ns}) \\
-\mathbf{2 . 1 1} \pm \mathbf{0 . 2 8}\left({ }^{* *}\right)\end{array}$ & $-1.1 \pm 0.9(\mathrm{~ns})$ & $0.2 \pm 1.3(\mathrm{~ns})$ & $\begin{array}{l}1 \\
0\end{array}$ & $\begin{array}{l}-0.55 \pm 0.27\left(^{*}\right) \\
-\mathbf{0 . 4 8} \pm \mathbf{0 . 2 0}\left({ }^{*}\right)\end{array}$ \\
\hline
\end{tabular}

duction rates depend on the time required for gonad maturation, which is related to the use of storage lipids, food supply, and temperature (Plourde \& Runge 1993, Niehoff et al. 2002). Niehoff et al. (2002) observed $45 \%$ C. glacialis with fully developed gonads in Disko Bay in mid-March 1996 and only $10 \%$ C. finmarchicus. The relative contribution of $C$. finmarchicus to the biomass may therefore be expected to be reduced if the bloom initiates earlier in the future, unless increased temperatures accelerate the gonad maturation rate considerably. The relatively high egg production of $C$. glacialis at all temperatures and that of $C$. finmarchicus at high temperatures $\left(>5^{\circ} \mathrm{C}\right)$ cannot be supported by the grazing alone, assuming that ingested carbon was converted into eggs by an efficiency of $36 \%$ as seen for Acartia tonsa (Kiørboe et al. 1985). Grazing only accounts for approximately half of the egg production, and the remainder would have to be supported by use of internal lipids (Table 7).

Based on the discussion above, one could be tempted to conclude that Calanus glacialis would be better adapted to an early bloom with a relatively small temperature increase. However, C. glacialis may have a multiple year life cycle as adults (Conover 1988, Kosobokova 1999, Madsen et al. 2001, Swalethorp et al. 2011). Thus, it is important to stress that $C$. glacialis did not refuel their lipid stores during the early bloom experiment, contrary to the bloom experiment (Table 7). It is therefore doubtful that C. glacialis will survive the following hibernation period, if the same strategy prevails in a future warmer climate, because food probably will be much less abundant at the time of refueling. The comparable or higher egg production by $C$. finmarchicus at higher temperatures $\left(>2.5^{\circ} \mathrm{C}\right)$ suggests that the bio- mass of $C$. finmarchicus would increase in a warmer future. However, it is important to note that a quick response to the phytoplankton bloom is crucial for realizing this success (Varpe et al. 2007), and only those nauplii initiating feeding at or shortly after the onset of the bloom will survive (Ringuette et al. 2002). In Disko Bay, C. glacialis initiate gonad maturation up to 5 wk before $C$. finmarchicus (Niehoff et al. 2002) and will therefore respond faster in an early bloom situation (Fig. 3). At the same time, gonads and oocytes will mature faster with increasing temperatures (Plourde \& Runge 1993, Niehoff 2007), and the development time from spawning to the first feeding nauplius stage will decrease as the temperature increases (Cook et al. 2007, Bonnet et al. 2009). This will also enable nauplii from later spawned eggs to feed in the bloom, which will be an advantage for C. finmarchicus.

The grazing and reproduction potential of the 2 Calanus species before the bloom were evaluated in the starved bloom experiment. Here the potential specific egg production responded to temperature by a factor of 26.6 for C. finmarchicus and by a factor of 4.2 for C. glacialis. The in situ female spawning percentage at the initiation of the experiment was $0 \%$ for C. finmarchicus and $5.3 \%$ for C. glacialis at $-1.5^{\circ} \mathrm{C}$ (Swalethorp et al. 2011) and with $0.08 \mu \mathrm{g} \mathrm{chl}$ $a \mathrm{l}^{-1}$ in the upper $50 \mathrm{~m}$ (Dünweber et al. 2010). This documents that $C$. glacialis is capable of producing eggs prior to the bloom without feeding (Smith 1990), fueled by stored lipids (Hirche \& Kattner 1993). However, the findings for C. finmarchicus are in contradiction to earlier findings (Smith 1990, Plourde \& Runge 1993). Although production by C. finmarchicus has also been observed without food, this was only in a minority of the population (Plourde \& Runge 
Table 9. Calanus finmarchicus and C. glacialis. Effects of food availability and temperature on changes in lipid content. Parameter values are given \pm SE and $p$ levels are indicated(p $\left.>0.05[\mathrm{~ns}],{ }^{*} \mathrm{p}<0.05,{ }^{* *} \mathrm{p}<0.01,{ }^{* * *} \mathrm{p}<0.001\right)$. Significant differences between species ( $\left.\mathrm{p}<0.05\right)$ are indicated in bold. TAG: triacylglycerol

\begin{tabular}{|c|c|c|c|c|c|c|c|}
\hline Intercept & $k_{\text {food }}$ & food & $k_{\text {temp }}$ & Intercept & $k_{\text {food }}$ & food & $k_{\text {temp }}$ \\
\hline \multicolumn{8}{|c|}{ Change in total lipid content $(\%)=$ intercept $+\left(k_{\text {food }} \times\right.$ food $)+\left(k_{\text {temp }} \times\right.$ temp $)$, with and without food } \\
\hline \multicolumn{4}{|c|}{ C. finmarchicus - pre-bloom } & \multicolumn{4}{|c|}{ C. glacialis - pre-bloom } \\
\hline \multirow[t]{2}{*}{$-32 \pm 10\left({ }^{* *}\right)$} & $-10 \pm 14(\mathrm{~ns})$ & 1 & $-2.2 \pm 1.6(\mathrm{~ns})$ & $-32 \pm 17(\mathrm{~ns})$ & $19 \pm 23(\mathrm{~ns})$ & 1 & $-6.3 \pm 2.6\left(^{*}\right)$ \\
\hline & & 0 & $-1.6 \pm 1.7(\mathrm{~ns})$ & & & 0 & $-0.1 \pm 2.6(\mathrm{~ns})$ \\
\hline \multicolumn{4}{|c|}{ C. finmarchicus - bloom } & \multicolumn{4}{|c|}{ C. glacialis - bloom } \\
\hline \multirow[t]{2}{*}{$-57 \pm 6\left({ }^{* * *}\right)$} & $12 \pm 8(\mathrm{~ns})$ & 1 & $-2.7 \pm 0.9\left({ }^{* *}\right)$ & $-54 \pm 21\left(^{*}\right)$ & $87 \pm 38\left(^{*}\right)$ & 1 & $-4.8 \pm 4.7(\mathrm{~ns})$ \\
\hline & & 0 & $-3.7 \pm 1.1\left(^{* *}\right)$ & & & 0 & $4.4 \pm 3.4(\mathrm{~ns})$ \\
\hline \multicolumn{4}{|c|}{ C. finmarchicus - post-bloom } & \multicolumn{4}{|c|}{ C. glacialis - post-bloom } \\
\hline \multirow[t]{2}{*}{$-45 \pm 0.5\left({ }^{* * *}\right)$} & $0 \pm 7(\mathrm{~ns})$ & 1 & $-2.7 \pm 0.8\left(^{* *}\right)$ & $-1 \pm 12(\mathrm{~ns})$ & $-19 \pm 20(\mathrm{~ns})$ & 1 & $0.03 \pm 2.3(\mathrm{~ns})$ \\
\hline & & 0 & $-3.7 \pm 0.8\left(^{* * *}\right)$ & & & 0 & $-1.4 \pm 2(\mathrm{~ns})$ \\
\hline \multicolumn{8}{|c|}{ Change in TAG content $(\%)=$ intercept $+\left(k_{\mathrm{food}} \times\right.$ food $)+\left(k_{\text {temp }} \times\right.$ temp $)$, with and without food } \\
\hline \multicolumn{4}{|c|}{ C. finmarchicus - pre-bloom } & \multicolumn{4}{|c|}{ C. glacialis - pre-bloom } \\
\hline \multirow[t]{3}{*}{$17 \pm 751(\mathrm{~ns})$} & $2295 \pm 1060\left(^{*}\right)$ & 1 & $51 \pm 126(\mathrm{~ns})$ & $-23 \pm 161(\mathrm{~ns})$ & $465 \pm 223\left({ }^{*}\right)$ & 1 & $-13 \pm 25(\mathrm{~ns})$ \\
\hline & & 0 & $17 \pm 134(\mathrm{~ns})$ & & & 0 & $50 \pm 25\left(^{*}\right)$ \\
\hline & C. finmarchicus - & & & & C. glacialis - & om & \\
\hline \multirow[t]{3}{*}{$593 \pm 862(\mathrm{~ns})$} & $4657 \pm 1204\left(^{* *}\right)$ & 1 & $-205 \pm 137(\mathrm{~ns})$ & $-61 \pm 38(\mathrm{~ns})$ & $171 \pm 71\left(^{*}\right)$ & 1 & $4.5 \pm 8.8(\mathrm{~ns})$ \\
\hline & & 0 & $-66 \pm 165(\mathrm{~ns})$ & & & 0 & $1.9 \pm 6.2(\mathrm{~ns})$ \\
\hline & C. finmarchicus - & oom & & \multicolumn{4}{|c|}{ C. glacialis - post-bloom } \\
\hline \multirow[t]{2}{*}{$19 \pm 22(\mathrm{~ns})$} & $50 \pm 32(\mathrm{~ns})$ & 1 & $-8.1 \pm 3.7\left({ }^{*}\right)$ & $-54 \pm 22\left({ }^{*}\right)$ & $-24 \pm 35(\mathrm{~ns})$ & 1 & $6.4 \pm 4.1(\mathrm{~ns})$ \\
\hline & & 0 & $-8.5 \pm 3.7\left(^{*}\right)$ & & & 0 & $-1.4 \pm 3.5(\mathrm{~ns})$ \\
\hline \multicolumn{8}{|c|}{ Change in phospholipid content $(\%)=$ intercept $+\left(k_{\text {food }} \times\right.$ food $)+\left(k_{\text {temp }} \times t e m p\right)$, with and without food } \\
\hline \multicolumn{4}{|c|}{ C. finmarchicus - pre-bloom } & \multicolumn{4}{|c|}{ C. glacialis - pre-bloom } \\
\hline \multirow[t]{3}{*}{$13 \pm 65(\mathrm{~ns})$} & $332 \pm 92\left({ }^{* *}\right)$ & 1 & $9.2 \pm 11.0(\mathrm{~ns})$ & $65 \pm 33(\mathrm{~ns})$ & $70 \pm 46(\mathrm{~ns})$ & 1 & $-6.0 \pm 5.1(\mathrm{~ns})$ \\
\hline & & 0 & $-0.1 \pm 11.7(\mathrm{~ns})$ & & & 0 & $-6.7 \pm 5.1(\mathrm{~ns})$ \\
\hline & C. finmarchicus - & & & & C. glacialis - & om & \\
\hline \multirow[t]{2}{*}{$75 \pm 12\left({ }^{* * *}\right)$} & $76 \pm 16\left(^{* * *}\right)$ & 1 & $-7.2 \pm 1.9\left(^{* * *}\right)$ & $-5 \pm 16(\mathrm{~ns})$ & $55 \pm 31(\mathrm{~ns})$ & 1 & $-1.0 \pm 3.8(\mathrm{~ns})$ \\
\hline & & 0 & $-16.4 \pm 2.3\left({ }^{* * *}\right)$ & & & 0 & $0.8 \pm 2.7(\mathrm{~ns})$ \\
\hline \multicolumn{4}{|c|}{ C. finmarchicus - post-bloom } & \multicolumn{4}{|c|}{ C. glacialis - post-bloom } \\
\hline \multirow[t]{2}{*}{$57 \pm 11\left({ }^{* * *}\right)$} & $-3.8 \pm 16(\mathrm{~ns})$ & 1 & $-4.8 \pm 1.8\left(^{*}\right)$ & $-5 \pm 12(\mathrm{~ns})$ & $9.5 \pm 19(\mathrm{~ns})$ & 1 & $-3.3 \pm 2.6(\mathrm{~ns})$ \\
\hline & & 0 & $-9.5 \pm 1.8\left(^{* * *}\right)$ & & & 0 & $-1.2 \pm 2.0(\mathrm{~ns})$ \\
\hline Change in wax & ester content $(\%)=$ & ept + & $\left(k_{\text {food }} \times\right.$ food $)+\left(k_{\mathrm{te}}\right.$ & $n p$ ), with and w & out food & & \\
\hline & C. finmarchicus - & oom & & & C. glacialis - $\mathbf{p}$ & loom & \\
\hline$-33 \pm 11\left({ }^{* *}\right)$ & $-25 \pm 13(\mathrm{~ns})$ & 1 & $-2.7 \pm 1.6(\mathrm{~ns})$ & $-39 \pm 17\left(^{*}\right)$ & $12 \pm 23(\mathrm{~ns})$ & 1 & $-6.3 \pm 2.6\left(^{*}\right)$ \\
\hline & & 0 & $-1.7 \pm 1.7(\mathrm{~ns})$ & & & 0 & $-0.0 \pm 2.5(\mathrm{~ns})$ \\
\hline & C. finmarchicus - & & & & C. glacialis - & & \\
\hline$-72 \pm 7\left(^{* *}\right)$ & $3 \pm 9(\mathrm{~ns})$ & 1 & $-1.9 \pm 1.3(\mathrm{~ns})$ & $-73 \pm 27\left(^{*}\right)$ & $93 \pm 51(\mathrm{~ns})$ & 1 & $-7.0 \pm 6.2(\mathrm{~ns})$ \\
\hline & & 0 & $-2.4 \pm 1.1(\mathrm{~ns})$ & & & 0 & $6.0 \pm 4.4(\mathrm{~ns})$ \\
\hline & C. finmarchicus - & loom & & & C. glacialis - pc & loom & \\
\hline$-71 \pm 5\left(^{* *}\right)$ & $3.5 \pm 7(\mathrm{~ns})$ & 1 & $-1.8 \pm 0.8\left(^{*}\right)$ & $2.7 \pm 14(\mathrm{~ns})$ & $-22 \pm 22(\mathrm{~ns})$ & 1 & $-0.1 \pm 2.6(\mathrm{~ns})$ \\
\hline & & 0 & $-2.1 \pm 0.8\left(^{*}\right)$ & & & 0 & $-1.5 \pm 2.2(\mathrm{~ns})$ \\
\hline
\end{tabular}

1993). Richardson et al. (1999) as well as M.L. Madsen et al. (2008) suggested that C. finmarchicus also use their lipid stores for this early egg production. Our study confirms that starved C. finmarchicus produce eggs (Richardson et al. 1999), albeit at a very low specific rate, below $5^{\circ} \mathrm{C}\left(<0.1 \% \mathrm{~d}^{-1}\right)$ and subsequently SEP increases with temperature to a level similar to that detected for C. glacialis (Fig. 6a). This is in line with Melle \& Skjoldal (1998), who, based on their findings of eggs collected in the water column, concluded that pre-bloom spawning was equal in both C. finmarchicus and C. glacialis when environmental conditions (e.g. warm winter temperature) allowed early gonad maturation. 
Richardson et al. (1999) found that $20 \mu \mathrm{g}$ of lipid could fuel the production of approximately 100 eggs for Calanus finmarchicus. This corresponds well to the egg production and extra lipid loss recorded in the 7.5 and $10^{\circ} \mathrm{C}$ experiments for $C$. finmarchicus (Table 7). The lipid loss of approximately $37 \mu \mathrm{g}$ $(\sim 50 \%)$ body lipid observed for $C$. finmarchicus at 0 to $5^{\circ} \mathrm{C}$, where egg production was very low, could probably meet the energy demand of maturing the gonads and oocytes. Similar results have also been observed by Jónasdóttir (1999). The very low TAG content in the initial samples (Table 7) suggests that neither of the species had been feeding, as TAG is a dietary lipid (Hakanson 1984), excluding possibly feeding on ice algae. Based on this study, temperature may be a limiting factor for the potential egg production by $C$. finmarchicus prior to a bloom as well as in an early bloom situation, as proposed by Melle \& Skjoldal (1998), but contradicting Hirche (1990).

Using FP production as a proxy for grazing makes no sense for the starved treatment. The observed FP production must be due to forced elimination of the intestinal epithelium (Besiktepe \& Dam 2002) fueled by lipids. This is also supported by the appearance of the FPs (Fig. 7). Similar whitish-transparent FPs have also been observed by Seuthe et al. (2007). The enhanced FP productions at increasing temperature for both species indicate that forced elimination of the intestinal epithelium is temperature dependent (Fig. 6). The mean increase in potential egg production at all tested temperatures between fed and starved copepods was 7 -fold for C. glacialis and 12fold for $C$. finmarchicus. This supports earlier findings on the close relationship between food availability and egg production (Marshall \& Orr 1952, Runge 1985, Smith 1990, Hirche \& Kattner 1993, Niehoff et al. 2002), and highlight that both species are able to increase egg production the most when offered food (Hirche \& Kattner 1993, Hirche \& Kosobokova 2007).

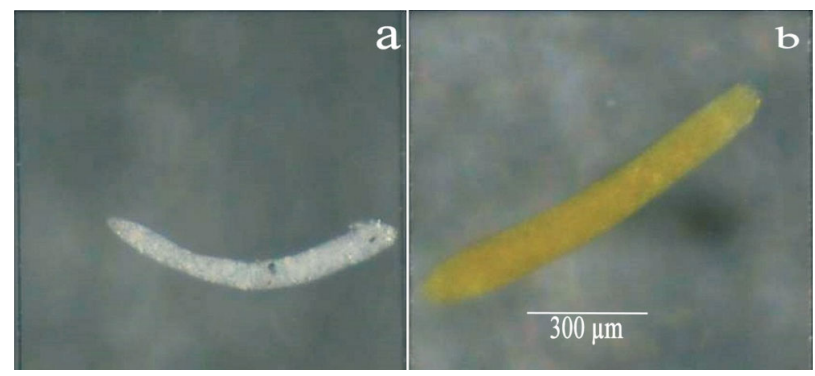

Fig. 7. Calanus glacialis. Example of a fecal pellet from (a) the starved treatment (ghost pellet) and (b) the treatment where food was available

\section{Scenario 2: Unchanged timing of the spring phytoplankton bloom}

We investigated the effect of increasing temperatures during the bloom by collecting copepods just at the initiation of the phytoplankton bloom (Fig. 1, Table 4) and offering them an unlimited supply of food.

Both species were grazing at a higher rate at all temperatures during the bloom experiment compared to the pre- and post-bloom experiments. In parallel, an increase in TAG content was measured, revealing recent feeding activity (Hakanson 1984). TAG accumulated during feeding and was used for egg production or converted into WE for long-term storage (Lee et al. 2006). However, the presence of TAG as well as WE can also indicate egg production, as they each make up about $15 \%$ of the egg lipids; however, PL accounted for the rest ( $70 \%$; Ohman \& Runge 1994) and are therefore a strong indicator of egg production (Swalethorp et al. 2011). The higher specific grazing rate did not result in a corresponding increase in SEP compared to the pre-bloom. Instead, Calanus glacialis were refueling their WE stores likely in preparation to overwinter again (Table 7; Kosobokova 1999, Swalethorp et al. 2011). C. finmarchicus was not refueling but seemed to prioritize reproduction. The comparable egg and FP production rates found in situ (Swalethorp et al. 2011) during this phase of the bloom confirm the use of Thalassiosira weissflogii as a good food object for both species.

The potential specific egg production responded by a factor of 3.5 for Calanus glacialis between 0 and $10^{\circ} \mathrm{C}$. For C. finmarchicus, the production increased up to a factor of 25 at 7.5 and $10^{\circ} \mathrm{C}$. C. glacialis had the highest specific egg production of the 2 species at temperatures below $5^{\circ} \mathrm{C}$ and was at the same time refueling, contrary to the pre-bloom experiment (Table 7). The specific egg production for $C$. finmarchicus at $0{ }^{\circ} \mathrm{C}$ was $0.6 \% \mathrm{~d}^{-1}$ and similar to what was detected in the pre- and post-bloom experiment. This is much lower than the $4 \% \mathrm{~d}^{-1}$ (Hirche et al. 1997 ) and $4.5 \% \mathrm{~d}^{-1}$ (Hirche 1990 ) reported at $0^{\circ} \mathrm{C}$ in the Greenland Sea at unlimited food conditions. The large difference to this study cannot be explained by the use of a slightly different conversion factor, but rather by the experimental precondition, which will be discussed later.

Madsen et al. (2001) observed a similar low SEP rate $\left(0.5\right.$ to $\left.1.2 \% \mathrm{~d}^{-1}\right)$ during the bloom in May 1996 in a study in Disko Bay. Based on parallel gonad index measurements, they argued that gonad devel- 
opment had been slowed down due to the low temperatures resulting in this mismatch. A later initiation of the bloom experiment would probably have increased the egg production (S.J. Madsen et al. 2008). As the gonads mature up to $5 \mathrm{wk}$ earlier in Calanus glacialis (Niehoff et al. 2002), they are less vulnerable to an early initiation of the bloom than C. finmarchicus. The reported findings by Hirche (1990) and Hirche et al. (1997) correspond to the rate observed between 5 and $7.5^{\circ} \mathrm{C}$ in this study. Hirche \& Kosobokova (2007) used data from Hirche et al. (1997) to make comparisons between temperature effects on the egg production of C. finmarchicus and C. glacialis, and found that $C$. finmarchicus had the highest egg production at all tested temperatures $(-1.5$ to $8^{\circ} \mathrm{C}$ ). In our study, it was only at $10^{\circ} \mathrm{C}$ that $\mathrm{C}$. finmarchicus had the highest specific egg production, almost double that of C. glacialis (15.7 and $8.1 \% \mathrm{~d}^{-1}$, respectively).

At the initiation of the bloom experiment, $11 \%$ of Calanus finmarchicus and $55 \%$ of C. glacialis were spawning (Swalethorp et al. 2011). The temperature-dependent increase in C. finmarchicus cumulative grazing used for egg production indicates that the fraction of females with mature gonads increased with temperature, as during the prebloom. The fact that C. glacialis had the highest potential carbon-specific egg production at $\leq 5^{\circ} \mathrm{C}$ suggests that C. glacialis may continue to be dominant in areas that do not exceed approximately $5^{\circ} \mathrm{C}$ during the spawning period. However, the duration of gonad maturation and oocyte maturation decrease considerably with only small increases in temperature (Niehoff et al. 2002, Niehoff 2007), and $C$. finmarchicus will therefore probably match the bloom in a future warmer climate at a less pronounced temperature increase. Hirche \& Kosobokova (2007) found that C. finmarchicus had a higher egg production than C. glacialis even at $-1.5^{\circ} \mathrm{C}$ based on data from Hirche et al. (1997) (Fig. 8). However, it is important to stress that the C. finmarchicus used by Hirche et al. (1997) were taken from $9^{\circ} \mathrm{C}$ water and then acclimatized to $0^{\circ} \mathrm{C}$ for 4 to $7 \mathrm{~d}$ prior to the study. These preconditions obviously increased the proportion of $C$. finmarchicus with mature gonads and oocytes to an artificially high level. The tipping point for a change in the biomass composition depends on duration, rate, and magnitude of the temperature increase. A $1{ }^{\circ} \mathrm{C}$ increase in the surface during the phytoplankton bloom in 1996 to 1997 resulted in an increase in SEP during the bloom for $C$. finmarchicus from $0.5-1.2 \% \mathrm{~d}^{-1}$ to $2.4-5.3 \% \mathrm{~d}^{-1}$ (Madsen et al. 2001,

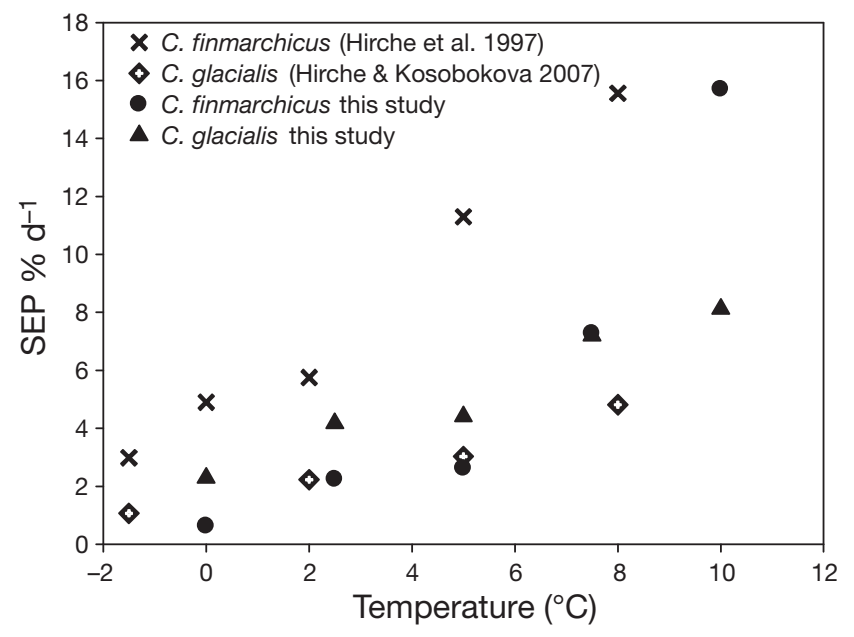

Fig. 8. Calanus finmarchicus and C. glacialis. Specific egg production (SEP) during the bloom compared to SEP calculated based on data from Hirche \& Kosobokova (2007) and Hirche et al. (1997), assuming a mean carbon content of both copepods during bloom conditions (see Table 7) as well as similar egg carbon content (see Table 3) as used in this study

Niehoff et al. 2002) assuming similar carbon content and egg volume as in this study. The low production in 1996 is explained by the low share of C. finmarchicus with mature gonads in 1996 as a consequence of the $1^{\circ} \mathrm{C}$ difference. For C. glacialis, an increase was also detected from $2.5 \% \mathrm{~d}^{-1}$ in 1996 to $3.4 \% \mathrm{~d}^{-1}$ in 1997 (Madsen et al. 2001). Considering the in situ temperatures, it is also crucial to know whether the time spent at the surface is enough to trigger the high production detected for C. finmarchicus at $>5^{\circ} \mathrm{C}$.

Calanus finmarchicus accounted for $73 \%$ and $C$. glacialis only $27 \%$ of the adult biomass of the 2 species in Disko Bay during the spring and early summer of 2008 (Swalethorp et al. 2011). Biomass is influenced by recruitment in previous years as well as by predation. Sea-ice coverage was low in 2003 to 2007 in Disko Bay (Artic Station monitoring program). Even though the bay has been partly ice-free, only the surface water has experienced temperature increases, but the large fraction of adult $C$. finmarchicus supports the notion that the short time spent in the warmer surface layer is enough to trigger high egg production, as documented at high temperatures in the present study. The total in situ specific egg production in 2008 was almost twice as high for $C$. glacialis as for C. finmarchicus between 21 February and 19 May (end of the in situ bloom) while SEP of $C$. finmarchicus was 4 times higher than that of $C$. glacialis in the period 19 May to 18 July (Swalethorp et al. 2011). In the 2 periods, the surface temperature 
increased gradually from -1.7 to $2^{\circ} \mathrm{C}$ in the first period and from 2 to $10^{\circ} \mathrm{C}$ in the latter period. Eggs spawned at the end of or after the spring bloom may have a lower survival probability (Varpe et al. 2007), and the ratio of $C$. glacialis could then be expected to have increased in 2009 assuming the same hatching percentage and predation pressure. Melle \& Skjoldal (1998) found that the majority of the eggs of $C$. finmarchicus was collected in the water column during the late bloom in the Barents Sea polar front region, whereas in the Barents Sea Atlantic water, >95\% of the eggs were spawned during the bloom mainly as a result of the temperature difference. Assuming the time spent in the warmer surface water is enough to trigger the high production, $C$. finmarchicus will be an even more dominant species in areas like Disko Bay (Madsen et al. 2001) within the next century, as sea-surface temperature is expected to increase by 4 to $7^{\circ} \mathrm{C}$ in the Arctic (ACIA 2004). A further northward migration of $C$. finmarchicus and stronger competition with $C$. glacialis require that they also reproduce in those areas. Hirche \& Kosobokova (2007) did find C. finmarchicus present at all stations investigated on their cruise across the central Greenland Sea, but they only found developmental stages (CI-CIV) close to regions of submergence of Atlantic water under the polar water, indicating no reproducing population in the polar waters. Our study indicates that temperatures close to $0^{\circ} \mathrm{C}$ in the bloom period could be limiting for reproduction, as gonad maturation is delayed, influencing the reproductive success of $C$. finmarchicus, in contradiction with Hirche (1990). Knowledge about temperature tolerance of the development stages is essential to conclude whether C. finmarchicus possibly could reproduce in polar water. Based on sampling with high vertical resolution, Sameoto (1984) showed that C. finmarchicus CII-CIV preferred to be located in the warmer surface layer above the upper part of the thermocline, whereas $\mathrm{CV}$ and adults preferred to be just below the thermocline, indicating different ontogenetic temperature preferences.

Copepods collected at the initiation of the bloom were also starved to investigate reproduction based on stored reserves. The copepods used in the bloom experiment had experienced an average phyto-

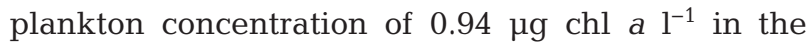
upper $50 \mathrm{~m}$, whereas the concentration at $1 \mathrm{~m}$ depth was above $15 \mu \mathrm{g} \mathrm{chl} \mathrm{a} \mathrm{l}^{-1}$ (Table 4). The TAG measurements suggested limited feeding prior to the experiment. This higher production is also reflected in the exhausted body lipid reserves at the termination of the bloom experiment (Table 7).
Scenario 3: A prolonged spring phytoplankton bloom

In the post-bloom experiment, we mimicked a prolonged bloom by offering unlimited food to copepods collected in late May after the spring bloom. There was no effect of food on egg production. A weak effect was found on pellet production, but it was only significant for Calanus glacialis. (Fig. 6, Tables 6 \& 7). C. finmarchicus continued to produce FPs when offered food but only at a low rate of 1 to $3 \% \mathrm{~d}^{-1}$, whereas C. glacialis had terminated feeding prior to the overwintering period and produced $<1 \% \mathrm{~d}^{-1}$ at all temperatures. Moreover C. glacialis pellets also appeared similar to those in the starved treatment, indicating low or no grazing. There was a tendency to high temperature coefficients for both species when food was present, but the effect was not significant. The unchanged TAG measurements compared to the initial measurements support that C. glacialis was only feeding at a very low rate if at all (Tables 7 $\& 9)$. This has also been suggested by Levinsen et al. (2000). C. finmarchicus also had a higher but not significant specific egg production than C. glacialis, but both species only produced eggs at a very low rate. Melle \& Skjoldal (1998) also observed low egg abundance in the late-bloom for C. glacialis compared to C. finmarchicus in a study from the Barents Sea. The difference between the egg production of the 2 species is also clear in the PL measurements (Table 7), assuming that a substantial part of the females' PL content is bound in the membranes of eggs (Lee et al. 2006)

The effect of having experienced a pre-starved period prior to the experiment, which earlier was shown to have an effect on egg production (Hirche et al. 1997), was excluded in the present study by only using the production after the lag phase. Spawning percentage measured in situ in a parallel study was $50 \%$ for Calanus finmarchicus and only $15 \%$ for $C$. glacialis on 3 June 2008, a decrease from the maximum spawning of 80 and $100 \%$ observed on 2 May and 29 April, respectively (Swalethorp et al. 2011). Combined with a reduction in potential specific egg production at all tested temperatures of $>93 \%$ for $C$. glacialis and $>84 \%$ for $C$. finmarchicus $\left(>0^{\circ} \mathrm{C}\right) \mathrm{com}-$ pared to the bloom experiment, this suggests an endogenous control of the egg production in addition to food and temperature also proposed by Hirche et al. (1997). The increase in TL and WE detected in $C$. glacialis during the bloom experiment and between the bloom and the post-bloom experiment of $>7$-fold is a clear indication that $C$. glacialis refueled for the coming hibernation period, indicating a multiple year 
lifecycle as adults (Kosobokova 1999, Madsen et al. 2001, Swalethorp et al. 2011). The $100 \%$ spawning frequency observed for C. glacialis by Swalethorp et al. (2011) during the bloom also indicates that females in their second year can reproduce (Kosobokova 1999, Madsen et al. 2001). It cannot be excluded that some of the adult C. glacialis in the post-bloom had molted to adults during the spring, but the majority of $C$. glacialis and C. finmarchicus overwinter as stage CIII/CIV/CV and CV, respectively (Runge 1985, Lee et al. 2006, Falk-Petersen et al. 2009). C. finmarchicus then molt to adults the following winter/early spring (Marshall \& Orr 1952, Falk-Petersen et al. 2009), whereas C. glacialis probably needs 1 additional year to develop from CV to females (Scott et al. 2000, Falk-Petersen et al. 2009), depending on temperature and food conditions (Niehoff 2007). In contrast to C. glacialis, C. finmarchicus continued to decrease in lipid content across all 3 experiments, demonstrating a lifecycle including only 1 reproductive season (Scott et al. 2000, Falk-Petersen et al. 2009). During the post-bloom experiment, it is also important to note that $C$. glacialis lost lipid stores with increasing temperatures, and it is therefore important for C. glacialis to avoid the warmer surface layer in a warmer future, to successfully complete the hibernation period (Table 7).

In a prolonged bloom situation, pelagic secondary production is expected to increase, as food is a limiting factor for production (Kiørboe \& Nielsen 1994). Our study indicates that Calanus finmarchicus is able to exploit a longer season to a higher extent than $C$. glacialis (Figs. $3 \& 4$ ). This suggestion is supported by a parallel in situ study (Swalethorp et al. 2011) as well as by Melle \& Skjoldal (1998) and Kosobokova (1999). Survival of eggs spawned during the postbloom may, however, be expected to be low (Ringuette et al. 2002, Varpe et al. 2007), and the number of abnormal and unhealthy eggs has also been reported to increase late in the season (Marshall \& Orr 1952). Therefore, predictions of changing population dynamics based on egg production, like this study, should be made with some precautions. To fully elucidate the changes in the future Calanus community, the growth response of the smaller non-reproductive stages have to be investigated and considered. However, relatively high egg production in the postbloom period by C. finmarchicus (Swalethorp et al. 2011) may allow them to develop fast in the warm surface layer (Cook et al. 2007) if food is present. Temperature is the primary controlling factor on development time for Calanus helgolandicus (Bonnet et al. 2009), and this is most likely also true for $C$. finmarchicus and C. glacialis. A study by Sameoto (1984) also showed that CII to CIV of C. finmarchicus and C. glacialis are located above chl a max in the warmer surface layer, and thereby experience approximately $2^{\circ} \mathrm{C}$ warmer water than $\mathrm{CV}$ and adults placed just below the chl a max. In a warmer ocean, the population development rate will therefore likely speed up even more (Cook et al. 2007). Based on Corkett et al. (1986), we calculated that a temperature increase from 0 to $10^{\circ} \mathrm{C}$ reduces the development time from egg to CIV and CV from 107 and $85 \mathrm{~d}$ at $0^{\circ} \mathrm{C}$ to only 27 and $26 \mathrm{~d}$ at $10^{\circ} \mathrm{C}$ for $C$. finmarchicus and for C. glacialis, respectively. Part of the huge $C$. finmarchicus biomass seen in 2008 could originate from eggs spawned after the termination of the bloom in 2007, depending on whether the timing of the first feeding nauplii stages matched a secondary phytoplankton peak and spent time in the warmer surface layer. Grazing on ciliates and heterotrophic dinoflagellates may also support the late-developed copepods (Ohman \& Runge 1994, Turner et al. 2001).

\section{CONCLUSION}

Timing and duration of the spring bloom in a future warmer ocean will obviously affect secondary production. We suggest that a warmer ocean will cause a shift in the composition of the zooplankton community towards a more prominent role of the smaller, less energy-rich Calanus finmarchicus. The temperature threshold for when $C$. finmarchicus will be dominating in the Arctic waters will depend on (1) the timing of the bloom and (2) the magnitude of the temperature increase. The earlier the initiation of the bloom occurs, the higher a temperature increase will be required for $C$. finmarchicus to match the bloom. The adaptation to the variable Arctic conditions by C. glacialis, such as early spawning, will no longer be profitable when C. finmarchicus matches the bloom with mature gonads. In addition to this, the biomass accounted for by $C$. finmarchicus will increase (Hirche \& Kosobokova 2007) due to its higher growth rate and shorter lifecycle (Scott et al. 2000). The needed temperature increase for this shift to occur is overestimated in this study due to the precondition of low temperature during the winter. A smaller increase in temperature will result in a similar increase in egg production if the duration of exposure is prolonged (i.e. warmer winter temperatures). The water temperature increase required would rather be within $\sim 1$ to 
$2^{\circ} \mathrm{C}$ (Madsen et al. 2001) in Disko Bay and expectedly higher farther north (Scott et al. 2000). Temperature increases at this order of magnitude fall well within the modeled predictions for this century (ACIA 2004). A change in the competition of the Calanus-dominated Arctic mesozooplankton from lipid-rich Arctic species toward the smaller, less lipid-rich species will most likely affect the breeding success and composition of the higher trophic levels (Kitaysky \& Golubova 2000, Karnovsky et al. 2010).

Acknowledgements. This study was funded in collaboration between the Department of Bioscience, Aarhus University, Roskilde University (RU), University of Southern Denmark (SDU), Oticon, MODREC (contract no. 3304-FVFP-060683), SUNFISH (DSF contract no. 2101-07-0080), ECOGREEN (KVUG), Carlsberg Foundation, the Danish National Science Research Council project no. 272-07-0485, and the European Union Seventh Framework Program EUROBASIN (FP7/2007-2013) (ENV.2010.2.2.1-1 ENV.2010.2.2.11 ENV) under grant agreement no. 264933. We also thank B. Søborg, P. Christensen, and A. Faarborg for technical support, J. Carstensen for statistical guidance and Arctic Station Qeqertarsuaq, University of Copenhagen, for hosting us during the field work.

\section{LITERATURE CITED}

ACIA (Arctic Climate Impact Assessment) (2004) Impacts of a warming Arctic: synthesis report of the Arctic Climate Impact Assessment. Policy document prepared by the Arctic Council and presented at the 4th Arctic Council Ministerial Meeting, Reykjavik

Besiktepe S, Dam HG (2002) Coupling of ingestion and defecation as a function of diet in the calanoid copepod Acartia tonsa. Mar Ecol Prog Ser 229:151-164

Bonnet D, Harrie RP, Yebra L, Guilhaumon F, Conway DV, Hirst G (2009) Temperature effect on Calanus helgolandicus (Copepoda: Calanoida) development time and egg production. J Plankton Res 31:31-44

Buch E (1990) A monograph on the physical environment of Greenland waters. Sci Rep 00-12. Danish Meteorological Institute, Copenhagen. Available at www.dmi.dk/dmi/ dmi_sci.report_1._del.pdf)

Comiso JC (2002) A rapidly declining perennial sea ice cover in the Arctic. Geophys Res Lett 29:1956

> Conover RJ (1988) Comparative life histories in the genera Calanus and Neocalanus in high latitudes of the northern hemisphere. Hydrobiologia 167-168:127-142

Conover RJ, Huntley M (1991) Copepods in ice-covered seas-Distribution, adaptations to seasonally limited food, metabolism, growth patterns and life cycle strategies in polar seas. J Mar Syst 2:1-41

Cook KB, Bunker A, Hay S, Hirst AG, Speirs DC (2007) Nauplii development time and survival of the copepod Calanus helgolandicus and Calanus finmarchicus in relation to food and temperature. J Plankton Res 29: 757-767

Corkett CJ, McLaren IA, Sevigny JM (1986) The rearing of the marine calanoid copepods Calanus finmarchicus (Gunnerus), C. glacialis Jaschnov and C. hyperboreus
Kroyer with comment on the equiproportional rule. In: Shih CT (ed) Proc 2nd Int Conf Copepoda. Ottawa, Canada, 13-17 August 1984. Syllogeus 58:539-546

> Dünweber M, Swalethorp R, Kjellerup S, Nielsen TG, Møller EF, Tönnesson K, Arendt KE (2010) Succession and fate of the spring diatom bloom in the Disko Bay, western Greenland. Mar Ecol Prog Ser 419:11-29

Falk-Petersen S, Pavlov V, Timofeev S, Sargent JR (2007) Climate variability and possible effects on arctic food chains: the role of Calanus. In: Ørbæk JB, Tombre T, Kallenborn R, Hegseth E, Falk-Petersen S, Hoel AH (eds) Arctic alpine ecosystems and people in a changing environment. Springer-Verlag, Berlin, p 147-166

> Falk-Petersen S, Mayzaud P, Kattner G, Sargent JR (2009) Lipids and life strategy of Arctic Calanus. Mar Biol Res 5:18-39

> Hakanson JL (1984) The long and short term feeding condition in field-caught Calanus pacificus, as determined from the lipid content. Limnol Oceanogr 29:794-804

> Hansen AS, Nielsen TG, Levinsen H, Madsen SD, Thingstad $\mathrm{TF}$, Hansen BW (2003) Impact of changing ice cover on pelagic productivity and food web structure in Disko Bay, western Greenland: a dynamic model approach. Deep-Sea Res 50:171-187

Hansen BU, Elberling B, Humlum O, Nielsen N (2006) Meteorological trends (1991-2004) at Arctic Station, Central West Greenland $\left(69^{\circ} 15 \mathrm{~N}\right)$ in a 130 years perspective. Dan J Geogr 106:45-56

Hansen BW, Marker T, Anderassen P, Arashkewich E and others (2003) Difference in life-cycle traits of Calanus finmarchicus originating from $60^{\circ} \mathrm{N}$ and $69^{\circ} \mathrm{N}$, when reared in mesocosms at $69^{\circ} \mathrm{N}$. Mar Biol 142:877-893

Hansen MO, Nielsen TG, Stedmon CA, Munk P (in press) Oceanographic regime shift during 1997 in Disko Bay, Western Greenland. Limnol Oceanogr

Hansen PJ (1989) The red tide dinoflagellate Alexandrium tamarense: effect on behaviour and growth of a tintinnid ciliate. Mar Ecol Prog Ser 53:105-116

Hicks CR (1966) Fundamental concepts in the design of experiments. Holt-Saunders International Editions, New York, NY

- Hirche HJ (1990) Egg production of Calanus finmarchicus at low temperatures. Mar Biol 106:53-58

Hirche HJ, Kattner G (1993) Egg production and lipid content of Calanus glacialis in spring: indication of a fooddependent and food-independent reproductive mode. Mar Biol 117:615-622

> Hirche HJ, Kosobokova K (2003) Early reproduction and development of dominant calanoid copepods in the sea ice zone of the Barents Sea-need for a change of paradigms. Mar Biol 143:769-781

Hirche HJ, Kosobokova K (2007) Distribution of Calanus finmarchicus in the northern North Atlantic and Arctic Ocean-expatriation and potential colonization. Deep Sea Res II 54:2729-2747

> Hirche HJ, Mayer U, Niehoff B (1997) Egg production of Calanus finmarchicus: effect of temperature, food and season. Mar Biol 127:609-620

Holland DM, Thomas RH, DeYoung B, Ribergaard MH, Lyberth B (2008) Acceleration of Jakobshavn Isbræ triggered by warm subsurface ocean waters. Nat Geosci 1: 659-664

$>$ Hygum BH, Rey C, Hansen BW (2000) Growth and development rates of Calanus finmarchicus nauplii during a diatom spring bloom. Mar Biol 136:1075-1085 
Johnson CL, Leising AW, Runge JA, Head EJH, Pepin P, Plourde S, Durbin EG (2008) Characteristics of Calanus finmarchicus dormancy patterns in the Northwest Atlantic. ICES J Mar Sci 65:339-350

> Jónasdóttir SH (1999) Lipid content of Calanus finmarchicus during overwintering in the Faroe-Shetland Channel. Fish Oceanogr 8:61-72

Kahru M, Brotas V, Manzano-Sarabia M, Mitchell BG (2011) Are phytoplankton blooms occurring earlier in the Arctic? Glob Change Biol 17:1733-1739

Karnovsky NJ, Kwasniewski S, Weslawski JM, Walkusz W, Beszczynska-Möller A (2003) Foraging behavior of little auks in a heterogeneous environment. Mar Ecol Prog Ser 253:289-303

Karnovsky N, Harding A, Walkusz W, Kwa niewski S and others (2010) Foraging distributions of little auks Alle alle across the Greenland Sea: implications of present and future Arctic climate change. Mar Ecol Prog Ser 415: 283-293

> Kiørboe T, Nielsen TG (1994) Regulation of zooplankton biomass and production in a temperate, coastal ecosystem. 1. Copepods. Limnol Oceanogr 39:493-507

> Kiørboe T, Møhlenberg F, Hamburger K (1985) Bioenergetics of the planktonic copepod Acartia tonsa: relation between feeding, egg production and respiration, and composition of specific dynamic action. Mar Ecol Prog Ser 26:85-97

> Kitaysky AS, Golubova EG (2000) Climate change causes contrasting trends in reproductive performance of planktivorous and piscivorous alcids. J Anim Ecol 69:248-262

Kosobokova KN (1999) The reproductive cycle and life history of the Arctic copepod Calanus glacialis in the in the White Sea. Polar Biol 22:254-263

Laidre KL, Heide-Jørgensen MP, Nielsen TG (2007) Springtime foraging behavior of bowhead whales and ecosystem productivity in West Greenland. Mar Ecol Prog Ser 346:285-297

> Lee RF, Hagen W, Kattner G (2006) Lipid storage in marine zooplankton. Mar Ecol Prog Ser 307:273-306

> Levinsen H, Turner JT, Nielsen TG, Hansen BW (2000) On the trophic coupling between protists and copepods in arctic marine ecosystems. Mar Ecol Prog Ser 204:65-77

> Madsen ML, Gaard E, Hansen BW (2008b) Wax-ester mobilization by female Calanus finmarchicus (Gunnerus) during spring ascendance and advection to the Faroe Shelf. ICES J Mar Sci 65:1112-1121

- Madsen SD, Nielsen TG, Hansen BW (2001) Annual population development and production by Calanus finmarchicus, C. glacialis and C. hyperboreus in Disko Bay, western Greenland. Mar Biol 139:75-93

> Madsen SJ, Nielsen TG, Tervo OM, Sönderkvist J (2008a) Importance of feeding for the egg production in Calanus finmarchicus and C. glacialis during the Arctic spring. Mar Ecol Prog Ser 353:177-190

- Maps F, Plourde S, Zakardjian B (2010) Control of dormancy by lipid metabolism in Calanus finmarchicus: a population model test. Mar Ecol Prog Ser 403:165-180

> Marshall SM, Orr AP (1952) On the biology of Calanus finmarchicus VII. Factors affecting egg production. J Mar Biol Assoc UK 30:527-549

> Melle W, Skjoldal HR (1998) Reproduction and development of Calanus finmarchicus, C. glacialis and C. hyperboreus in the Barents Sea. Mar Ecol Prog Ser 169:211-228

> Niehoff B (2007) Life history strategies in zooplankton communities: the significance of female gonad morphology and maturation types of the reproductive biology of marine calanoid copepods. Prog Oceanogr 74:1-47

Niehoff B, Madsen SD, Hansen BW, Nielsen TG (2002) Reproductive cycles of three dominant Calanus species in Disko Bay, West Greenland. Mar Biol 140:567-576

Nielsen TG, Hansen B (1995) Plankton community structure and carbon cycling on the western coast of Greenland during and after the sedimentation of a diatom bloom. Mar Ecol Prog Ser 125:239-257

> Ohman MD, Runge JA (1994) Sustained fecundity when phytoplankton resources are in short supply: omnivory by Calanus finmarchicus in the Gulf of St. Lawrence. Limnol Oceanogr 39:21-36

> Plourde S, Runge JA (1993) Reproduction of planktonic copepod Calanus finmarchicus in the Lower St. Lawrence Estuary: relation to the cycle of phytoplankton production and evidence for a Calanus pump. Mar Ecol Prog Ser 102:217-227

> Reigstad M, Riser CM, Svensen C (2005) Fate of copepod faecal pellets and the role of Oithona spp. Mar Ecol Prog Ser 304:265-270

> Richardson K, Jónasdóttir SH, Hey SJ, Christoffersen A (1999) Calanus finmarchicus egg production and food availability in the Faroe-Shetland Channel and northern North Sea: October-March. Fish Oceanogr 8:153-162

Ringuette M, Fortier L, Fortier M, Runge JA and others (2002) Advanced recruitment and accelerated population development in Arctic calanoid copepods of the North Water. Deep Sea Res II 49:5081-5099

Runge JA (1985) Egg production rates of Calanus finmarchicus in the sea of Nova Scotia. Arch Hydrobiol 21:255-271

Rysgaard S, Nielsen TG, Hansen BW (1999) Seasonal variation in nutrients, pelagic primary production and grazing in a high-Arctic coastal marine ecosystem, Young Sound, Northeast Greenland. Mar Ecol Prog Ser 179:13-25

Sameoto DD (1984) Vertical distribution of zooplankton biomass and species in Northeastern Baffin Bay related to temperature and salinity. Polar Biol 2:213-224

SAS Institute (2004) SAS/STAT ${ }^{\circledR} 9.1$ user's guide. SAS Institute Inc., Cary, NC

Scott CL, Kwasniewski S, Falk-Petersen S, Sargent JR (2000) Lipids and life strategies of Calanus finmarchicus, Calanus glacialis and Calanus hyperboreus in late autumn, Kongsfjorden, Svalbard. Polar Biol 23:510-516

> Seuthe L, Darnis G, Riser C, Wassmann P, Fortier L (2007) Winter-spring feeding and metabolism of Arctic copepods: insights from faecal pellet production and respiration measurements in the southeastern Beaufort Sea. Polar Biol 30:427-436

Smith WO (1987) Phytoplankton dynamics in marginal ice zones. Oceanogr Mar Biol Annu Rev 25:11-38

Smith SL (1990) Egg production and feeding by copepods prior to the spring bloom of phytoplankton in Fram Strait, Greenland Sea. Mar Biol 106:59-69

Swalethorp R, Kjellerup S, Dünweber M, Nielsen TG, Møller EF, Rysgaard S, Hansen BW (2011) Production of Calanus finmarchicus, C. glacialis and C. hyperboreus in Disko Bay, western Greenland, with emphasis on life strategy. Mar Ecol Prog Ser 429:125-144

Tremblay JÉ, Gagnon J (2009) The effect of irradiance and nutrient supply on the productivity of Arctic waters: a perspective on climate change. In: Nihoul JCJ, Kostianoy AG (eds) Influence of climate change on the changing arctic and sub-arctic conditions. Springer, Dordrecht, p 73-93 
Turner JT, Levinsen H, Nielsen TG, Hansen BW (2001) Zooplankton feeding ecology: grazing on phytoplankton and predation on protozoans by copepod and barnacle nauplii in Disko Bay, West Greenland. Mar Ecol Prog Ser 221:209-219

Varpe O, Jørgensen C, Tarling GA, Fiksen Ø (2007) Early is better: seasonal egg fitness and timing of reproduction in a zooplankton life-history model. Oikos 116:1331-1342

Editorial responsibility: Edward Durbin, Narragansett, Rhode Island, USA
Varpe O, Jørgensen C, Tarling GA, Fiksen $\varnothing$ (2009) The adaptive value of energy storage and capital breeding in seasonal environments. Oikos 118:363-370

Wu Y, Peterson IK, Tang CCL, Platt T, Sathyendranath S, Fuentes-Yaco C (2007) The impact of sea ice on the initiation of the spring bloom on the Newfoundland and Labrador Shelves. J Plankton Res 29: $509-514$

Submitted: February 7, 2011; Accepted: December 12, 2011 Proofs received from author(s): February 6, 2012 